DIW BERLIN

Discussion

Papers

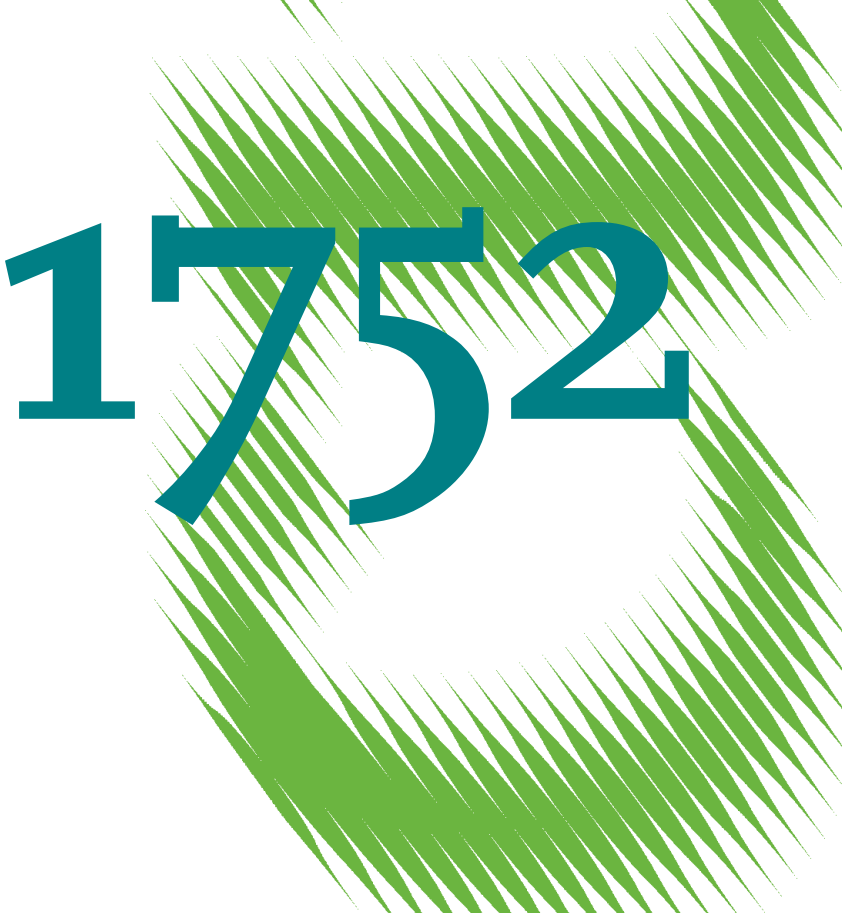

Social Image Concerns and

Welfare Take-Up 
Opinions expressed in this paper are those of the author(s) and do not necessarily reflect views of the institute.

IMPRESSUM

(C) DIW Berlin, 2018

DIW Berlin

German Institute for Economic Research

Mohrenstr. 58

10117 Berlin

Tel. +49 (30) $89789-0$

Fax +49 (30) $89789-200$

http://www.diw.de

ISSN electronic edition 1619-4535

Papers can be downloaded free of charge from the DIW Berlin website:

http://www.diw.de/discussionpapers

Discussion Papers of DIW Berlin are indexed in RePEc and SSRN:

http://ideas.repec.org/s/diw/diwwpp.html

http://www.ssrn.com/link/DIW-Berlin-German-Inst-Econ-Res.html 


\title{
Social Image Concerns and Welfare Take-Up*
}

\author{
Jana Friedrichsen \\ Tobias König \\ Renke Schmacker
}

July 27, 2018

\begin{abstract}
Using a laboratory experiment, we present first evidence that social image concerns causally reduce the take-up of an individually beneficial transfer. Our design manipulates the informativeness of the take-up decision by varying whether transfer eligibility is based on ability or luck, and how the transfer is financed. We find that subjects avoid the inference both of being low-skilled (ability stigma) and of being willing to live off others (free-rider stigma). Using a placebo treatment, we exclude other explanations for the observed stigma effects. Although stigma reduces take-up, elicitation of political preferences reveals that only a minority of "taxpayers" vote for the public transfer.
\end{abstract}

JEL-codes: C91, D03, H31, I38

Keywords: stigma, signaling, redistribution, non take-up, welfare program

\footnotetext{
${ }^{*}$ We thank Vojta Bartos, Yves Breitmoser, Dirk Engelmann, Peter Haan, Eckhard Janeba, Georg Kirchsteiger, Dorothea Kübler, Johanna Möllerström, Daniel Müller, Julia Nafziger, and seminar participants at DIW Berlin, Aarhus University, Copenhagen Business School, University of Potsdam and University of Copenhagen for helpful comments. The paper also profited from discussions with conference participants at ESA 2016 (Bergen), the "Arne Ryde Workshop on Identity, Image and Economic Behavior, Image" (Lund), IMEBESS 2017 (Barcelona), the 2017 ZEW Public Finance Conference, the workshop "Different approaches towards measuring non-take-up" at the University of Antwerp, the workshop "Concerns for status and social image" at WZB Berlin, the VfS Annual Conference 2017 (Vienna), and the EEA 2017 (Lisbon). We further thank Adam Lederer for language editing help. We gratefully acknowledge financial support from the Deutsche Forschungsgemeinschaft through CRC TRR 190 and from the Leibniz Competition through the project SAW-2015-DIW-4.

Friedrichsen: DIW and Humboldt-Universität zu Berlin, jana.friedrichsen[at]hu-berlin[dot]de; König: WZB and Humboldt-Universität zu Berlin, t.koenig [at] hu-berlin[dot]de; Schmacker: DIW, rschmacker [at] diw $[$ dot $]$ de
} 


\section{Introduction}

In many economic situations, people not only care about their material outcomes, but also about maintaining a certain social image (Goffman, 1959; Bursztyn and Jensen, 2017). ${ }^{1}$ An influential theoretical literature builds on the assumption that individuals' desire to portray themselves in a socially favorable way is also highly relevant for their decision to take up welfare benefits (Moffitt, 1983; Besley and Coate, 1992; Lindbeck et al., 1999). The idea is that individuals eligible to claim a social transfer refrain from doing so because they do not want to send a negative signal about their ability, work motivation, or social attitudes, and because the resulting stigmatization may not only impair their self-worth but may also lead to inferior treatment by others (Stuber and Schlesinger, 2006). This so-called welfare stigma hypothesis has become key to explain the pervasive observation of incomplete take-up of social transfers in modern welfare states. ${ }^{2}$ Low take-up rates are a recurring theme in policy discussions because they indicate that a welfare program is ineffective in reaching its target group and in achieving its distributional goals (e.g., Eurofound, 2015). Despite the widespread usage of the welfare stigma hypothesis, empirical evidence supporting it is extremely scarce, mostly due to identification problems in the field (for a survey, see, e.g., Andrade, 2002; Currie, 2006). In this paper, we provide first evidence that social image concerns may causally affect an individuals' decision to claim a social transfer.

According to theory, social image concerns might affect an individual's take-up decision only if take-up is observed and informative about the claimant's "type," be it their income, ability, or pro-sociality. Thus, the ideal data set to test for the effect of social image concerns on welfare take-up would contain observations of take-up decisions in welfare programs that only differ in the visibility and the informational content of take-up. However, exogenous variation in either of these aspects is typically not available for real-world benefit systems. To the contrary, visibility usually correlates with the transaction costs associated with claiming a transfer (e.g., claiming online versus meeting up for a personal consultation), and the informativeness of take-up may well relate to the complexity of the application process for a certain benefit (e.g., amount of sensitive private information to be documented). These correlates cannot easily be controlled or even observed by the researcher in observational studies as well as in field experiments, such

\footnotetext{
${ }^{1}$ Social approval or image seeking explains how the desire to signal something about oneself can affect behavior. This effort can be instrumental as in Spence (1973) or have purely hedonic value (e.g., Gradwohl and Smorodinsky, 2017). In economics, social image concerns are studied, for instance, in conspicuous consumption (e.g., Bagwell and Bernheim, 1996; Corneo and Jeanne, 1997; Charles et al., 2009; Heffetz, 2011) and pro-social or charitable behavior (Glazer and Konrad, 1996; Bénabou and Tirole, 2006; Ariely et al., 2009).

${ }^{2}$ For instance, in the United States 37.7 percent did not claim Supplemental Security Income (SSI) in 2013 (US Department of Health and Human Services, 2016). In 2007-2009, about 38 percent of eligible adult US citizens without private health insurance were not part of the Medicaid program (Sommers and Epstein, 2010), and only 18 percent of all federally-eligible children received subsidized care through Child Care and Development Fund (CCDF) or related government funding streams in an average month in fiscal year 2009 (US Department of Health and Human Services, 2012). In the UK, more than a third of those entitled to claim Pension Credit failed to do so in 2014/15; thereby, missing out on an extra £2000 a year (Department of Work and Pensions, 2016). For Germany, estimates of non-take-up rates of social assistance lie between 40 and 50 percent (Bruckmeier and Wiemers, 2012), and higher for housing allowances and supplementary child allowances (Bruckmeier and Wiemers, 2017). Further, nutritional assistance is traditionally characterized by incomplete take-up, be it in the form of food stamps (Haider et al., 2003; Pinard et al., 2017) or free school lunches (Bhatia et al., 2011).
} 
that identification of the effect may fail. In this paper, we conduct a laboratory experiment that gives us control over the key aspects of social image, allowing us to draw causal inferences.

In our experiment, individuals must decide whether or not to take up a redistributive, social transfer. Eligibility for the transfer is based on income: Subjects with the lowest income are eligible to claim an income subsidy that is financed by tax revenues collected from the other group members. In our baseline treatment, income depends on performance. Though highly stylized, this experimental setup reflects important features of real-world means-tested benefit systems, which provide tax-financed cash (or cash-equivalent) benefits to individuals who earn low incomes in competitive economic environments.

Key to our design is that we experimentally manipulate the visibility of the take-up decision, i.e., whether claiming the social benefit is publicly observable or private information. Thus, we are able to measure whether individuals' take-up decisions respond to the (anticipated) social inference about both their economic performance (ability signaling) and their willingness to live off others (free-rider signaling). Further, in order to disentangle the relative importance of the two signaling concerns, we conduct a set of treatments that changes the informational content of the take-up decision. First, we let income be based on pure luck instead of performance. Second, we let the transfer be paid by the experimenter instead of other subjects. Finally, we analyze preferences about the transfer payment mode by letting individuals vote whether or not the transfer should be made publicly visible.

Our results reveal a significant and economically sizable stigma effect on transfer take-up: When transfer eligibility is based on performance, subjects are 30 percentage points less likely to take up a public, as compared to a private, redistributive transfer, even though the transfer amounts to a 50 percent increase in their payoff from 6 to 9 Euros. When we reduce the informational content of the take-up decision by letting eligibility depend on luck instead of performance, we still observe a sizable and significant stigma effect. However, it is significantly lower than in the treatment where eligibility is performance-based. In line with our theoretical framework, these results suggest that social image concerns comprise two important aspects. Subjects avoid the inference both of being low-skilled (ability stigma) and of being willing to live off others (free-rider stigma). We use an additional set of treatments in which claiming a transfer does not reduce other participants' income to exclude alternative explanations, like transaction costs and the signaling of meritocratic attitudes, for the observed treatment effect. The results from the voting stage reveal that more than half of those who pay for the transfer vote for the private transfer. Thus, they appear to have a positive willingness to pay to reduce welfare stigma as their own monetary payoff would be maximized by voting for the public mode.

We contribute to the literature on program participation by providing a cleanly identified stigma effect estimated from an economic experiment designed to capture the key aspects of a welfare program: income allocation in a competitive environment and redistribution through taxes and transfers. Our results suggest that individuals might deliberately refrain from participation in order to avoid public inferences about their type. Previous studies investigate how behavioral deficiencies, such as low program awareness, misperception of program features, and inattention affect program participation, with the conclusion that these contribute to incomplete take-up but cannot fully explain it (see, e.g., Madrian and Shea, 2001; Bhargava and Manoli, 
2015; Kleven and Kopczuk, 2011; Liebman and Luttmer, 2015; Finkelstein and Notowidigdo, 2018). We exclude these factors by design to focus on stigma, which earlier studies typically aimed to detect from surveys (see, e.g., Baumberg, 2016) in the form of an observed positive correlation between benefit size and the probability of welfare take-up (e.g., Blundell et al., 1988; Blank and Ruggles, 1996; Currie, 2000; Whelan, 2010), or from the observation that non take-up rates tend to be higher in means-tested (income-based) than in universal (non-income based) programs (see, e.g., Andrade, 2002). These approaches suffer from identification problems. In the first case, self-reported measures of experienced stigmatization and of take-up behavior might be biased because image-concerned individuals could shade their answers to stigma-related questions to avoid further stigmatization. In the second case, benefit size may depend on unobserved individual characteristics that also affect welfare take-up (e.g., assets or enrollment in further welfare programs) leading to omitted variable bias in the estimates. Further, the observed correlation could result from any transaction cost other than stigma.

An exception is the field experiment by Bhargava and Manoli (2015), designed to investigate the causes of incomplete take-up of earned income tax credits (EITC) in the US. Two of their treatments targeted stigma: a) a letter sent to tax filers emphasized that the benefits of the EITC are an earned consequence of "hard work"; and b) the letter communicated the high average take-up rate of the EITC. Neither of these two interventions was effective in improving take-up. While the interventions by Bhargava and Manoli (2015) are likely to influence "personal stigma," i.e., individuals' feelings of guilt or shame or a negative self-image from being on welfare, our treatment supposes that the psychic costs of welfare participation are related to (anticipated) beliefs of others about one's self ("social stigma") which are unlikely to play a role in their study because the EITC can be claimed privately. Both personal and social stigma have been hypothesized to influence welfare take-up (e.g., Bursztyn and Jensen, 2017). Our results support the irrelevance of personal stigma for take-up found also in Bhargava and Manoli (2015) as we find no systematic difference in take-up behavior between random and merit-based income in the private treatment. Yet, we find strong evidence for social stigma in the lab. To the best of our knowledge, no field experiment has tested whether an intervention that targets social stigma, for example, by increasing the anonymity of claiming a benefit, could positively impact take-up rates.

Our paper also relates to a growing literature that studies how social image or signaling concerns affect economic decisions in a variety of domains. ${ }^{3}$ Our contribution to this literature is twofold. First, we show that social image concerns also affect individuals' incentives in the welfare state, both when they decide about their own decision to take-up a welfare transfer and when they decide about the design of the take-up situation for others. Second, we show that concerns about social image in the take-up situation involve two dimensions, ability and

\footnotetext{
${ }^{3}$ Individuals are found to signal pro-social behavior in charitable giving and public good situations in the lab (e.g., Andreoni and Bernheim, 2009; Ariely et al., 2009), in the field (e.g., Rege and Telle, 2004; Soetevent, 2011), and to signal wealth, pro-social and sustainable attitudes in purchasing situations (Charles et al., 2009; Sexton and Sexton, 2014; Friedrichsen and Engelmann, 2018). Further studies find that social signaling affects work effort (Mas and Moretti, 2009), voting behavior and campaign contributions (DellaVigna et al., 2017; Perez-Truglia and Cruces, 2017), as well as financial decisions (Bursztyn et al., 2014).
} 
free-rider signaling, which we can study separately. ${ }^{4}$ Our public exposure treatment is similar to a treatment manipulation used, for instance, in Ewers and Zimmermann (2015), who show that individuals desire signaling high ability by overstating performance, and by McManus and Rao (2015), who find that individuals choose a more difficult task to signal higher intelligence when they have an audience.

Furthermore, we add to the literature that uses incentivized laboratory experiments to investigate preferences for redistribution and taxation with its potential interplay with social motives (see, e.g., Tyran and Sausgruber, 2006; Durante et al., 2014; Agranov and Palfrey, 2015). In contrast to these papers, we do not investigate what determines the preference for (the level of) redistribution per se but the circumstances under which transfers are paid. Our participants cannot influence transfer size or eligibility but they indirectly decide about the realized level of redistribution because the take-up rate differs systematically between private and public. We find that a large fraction of those subjects who effectively pay for the transfer, reveal a preference for keeping welfare claiming anonymous. This finding is consistent with the experiment of Eriksson et al. (2017), where subjects sacrifice resources to allow the worst performer in their group to save her face.

The paper proceeds as follows. In section 2, we present our experimental design and develop several testable predictions based on a theoretical framework that is contained in the appendix. In section 3 , we present our results with respect to individual take-up decisions, while in section 4 , we discuss individual voting behavior. Section 5 discusses policy implications and concludes.

\section{Experimental design and hypotheses}

We develop a $2 \times 2 \times 2$ design to cleanly test whether stigma contributes to low take-up rates and to disentangle possible sources of stigma in the laboratory. The treatment variations are the following. First, we implement possible stigmatization within-subject by varying whether the take-up of a transfer is public or private. Second, we vary between-subjects the informational content of take-up by letting eligibility depend on quiz performance or randomness. Third, we vary between-subjects whether the transfer is redistributive or subsidized by the experimenter.

\subsection{General setup}

Participants are matched in groups of three but never learn who is in their group. The experiment consists of three stages: (1) a general knowledge quiz; (2) the decision whether to claim a transfer for both a private and a public scheme; and (3) a vote about whether the transfer in the respective group should be paid out in private or in public.

In stage (1), all participants take part in a multiple choice quiz consisting of 18 general knowledge questions. ${ }^{5}$ Participants have six minutes to choose their answers. Each correctly

\footnotetext{
${ }^{4}$ Experimental studies on two-dimensional signaling are rare. Bracha and Vesterlund (2017) analyze how individual donations are affected by the desire to the signal income and generosity, showing that both are important in a laboratory experiment. In a field experiment, Bursztyn et al. (2018) show that also students desire to signal both high ability and low effort.

${ }^{5}$ The translated quiz is provided as a screenshot in the appendix.
} 
answered question is rewarded with one point, while wrongly answered or unanswered questions receive zero points. Depending upon the treatment introduced below, the instructions for stage (1) contain information on whether quiz performance will determine ranks within each group of three, or whether ranks will be allocated randomly within each group. Further, the instructions specify that final payment will be based on payout schedule A or B (cf. Table 1) conditional on decisions in later stages. We elicit beliefs about each participant's own performance directly after the quiz, and participants do not receive feedback at this stage.

Table 1: Payoffs schedule

\begin{tabular}{cccc}
\hline & & \multicolumn{2}{c}{ B } \\
\cline { 3 - 4 } rank & A & redistribution & subsidy \\
\hline 1 & 16 Euro & 14 Euro & 16 Euro \\
2 & 11 Euro & 10 Euro & 11 Euro \\
3 & 6 Euro & 9 Euro & 9 Euro \\
\hline
\end{tabular}

Notes: Table illustrates the payoff schedule for a given group. If the subject in rank 3 does not take up a transfer, schedule A is paid out in her group. If the subject in rank 3 takes up a transfer, schedule B is paid out in her group. Corresponding to the treatment the group is in, the transfer is either redistributive or subsidized by the experimenter.

In stage (2), we use the strategy method and ask each participant to decide whether or not to take up a transfer if she would rank third and depending on whether the take-up is paid out publicly or privately (for details see section 2.2 below). A participant's decision is implemented if, and only if, she ends up being ranked third and for the selected take-up mode. ${ }^{6}$ Taking up the transfer implies that in each respective group, payment schedule B is used instead of payment schedule A. When taking their decisions, participants do not know whether they will be eligible because feedback about their ranking is given to participants only after they have made their take-up decisions.

In stage (3), after the rank is revealed, each subject decides whether the private or the public treatment should become payoff-relevant for her group. In each group, the decision of one group member is drawn at random and is implemented for the respective group (random dictator voting).

Note that the instructions for stages (2) and (3) are only provided to the subjects after stage (1) is over. None of the instructions include information about the public or private transfer regime but these details are only given on-screen.

\footnotetext{
${ }^{6}$ This procedure is called the strategy method because each participant specifies a strategy. As the decision is only implemented if an individual is ranked third, which happens for each participant with positive probability, the procedure is incentive compatible. The advantage over a direct response method, where decisions are only made by those who actually are eligible, is that a decision is collected for every participant, thus not only generating more observations for a given budget but also yielding observations from comparable populations across treatments.
} 


\subsection{Treatments}

Public vs. private We vary the visibility of the transfer within subject by making transfer take-up public or private. In the public treatment, claiming a transfer requires the participant to walk through the lab and pick up a slip of paper at the experimenter's desk. In the private treatment, claiming a transfer only requires indicating the decision on the screen to have it included in the experimental payout. We use the strategy method to elicit the take-up decision from each participant for both the private and the public condition. All participants decide sequentially, on two separate screens, whether they want to claim the transfer if it is paid out privately and if it is claimed publicly. The order of decisions is randomized at the group level, i.e. for each group of three it is independently determined whether the private or the public decision has to be made first. The order of decisions does not affect behavior (see section 3.5 for details). The instructions emphasize that the take-up decision is binding, i.e., in case the participant is actually ranked third, the previously made decision will be executed. We ensure that all subjects adhere to their public take-up decision by asking them to enter the number written on the slip of paper into the computer program. The session can only continue once all public transfer claimants have entered this number.

Quiz vs. random We vary the informational content of the take-up decision by allocating ranks either according to quiz performance or randomly. In the quiz treatment, participants are informed in the first part of the instructions that they are ranked within their group by the number of correctly answered quiz questions. Ties are broken randomly. In the random treatment, they are informed that ranks are determined randomly and not affected by quiz performance. Nevertheless, we let subjects work on the knowledge quiz in both treatments to ensure that all sessions last the same amount of time. We chose the general knowledge quiz as it generates an informative signal about the ability of the participant without being very susceptible to differences in effort as the time budget was very generous.

Redistribution vs. subsidy While the transfer is redistributive in the majority of sessions, we also ran a set of sessions where the transfer is paid by the experimenter without affecting the payoffs of better ranked group members. We discuss below that this treatment variation allows us to cleanly test for free-rider signaling and to control for confounding explanations. In both treatments, participants are informed that claiming a transfer leads to payment schedule B in Table 1 but which schedule B is shown alternates between treatments. The instructions for stage (1) and the control questions are adjusted accordingly but everything else remains unchanged.

\section{$2.3 \quad$ Hypotheses}

In the following, we present our hypotheses. In appendix A, we show that these hypotheses can be derived from a simple social image model of welfare-take-up. Our general idea is that there are socio-psychological costs from being on welfare, which result from the fact that claiming a publicly visible social transfer may reveal negative information about one's type. For the quiz- 
redistribution treatment, we expect that the take-up rates are higher in the private condition than in the public condition: When take-up is anonymous, individuals do not fear the stigma of being a person with low ability or a person who is willing to take money from others. Denoting average take-up in the respective treatment by $t$, we predict:

Prediction 1 (Social signaling/welfare stigma). Take-up rates in the quiz-redistribution treatment are higher in the private than in the public setting: $t_{\text {priv,quiz,redist }}-t_{\text {pub,quiz,redist }}>0$.

In the random-redistribution treatment, welfare take-up is still associated with income losses of others. Assuming that individuals do not want to be perceived as a social free-rider (a person who lives off others), we also expect to see a public-private gap in this treatment.

Prediction 2 (Free-rider signaling). Take-up rates in the random-redistribution treatment are higher in the private than in the public setting: $t_{\text {priv,rand,redist }}-t_{\text {pub,rand,redist }}>0$.

However, unlike in the random-redistribution treatment, in the quiz treatment, take-up is informative about an individual's ability. Due to this scope for negative inferences about a claimant's ability, we predict that the quiz treatment induces more severe stigmatization because individuals do not want to be perceived as less able.

Prediction 3 (Ability signaling). The stigma effect is larger in the quiz than in the randomredistribution treatment: $\left(t_{\text {priv,quiz,redist }}-t_{\text {pub,quiz,redist }}\right)-\left(t_{\text {priv,rand,redist }}-t_{\text {pub,rand,redist }}\right)>0$.

Now, consider the subsidized treatments, in which claiming the transfer does not affect the payout of others. First, if some individuals find it costly to stand up and walk through the lab, take-up will be lower in public than in private, irrespective of any social image concern. Consequently, we would expect a public-private gap, even in the random-subsidized treatment where take-up is uninformative. However, the distance to the experimenter desk is quite short (at maximum 10 meters), such that picking up the slip of paper is not overly time-consuming, given the duration of the total experiment (45 to 60 minutes) and, thus, does not generate significant transaction costs. Therefore, we predict the public-private gap to disappear when the transfer is a subsidy and ranks are random.

Prediction 4 (Placebo test/transaction costs). The public-private gap disappears in the randomsubsidized treatment: $t_{\text {priv,rand,sub }}-t_{\text {pub,rand,sub }}=0$.

Second, as described above, take-up in the redistribution treatments carries a free-rider signal in both the quiz and the random treatment. We use the stigma effect in the random treatment as a measure for free-rider signaling since ability signaling cannot play a role there. However, when we change from quiz to random, we not only change what can be inferred about an individual's ability from taking the transfer. In addition, the income-generating mechanism is different. This may affect individuals' willingness to claim a social transfer. In particular, income might be seen as more deserved when it is based on performance rather than on pure luck. In the quiz-redistribution treatment, such meritocratic attitudes would lead to an increase in the take-up levels in the private setting when changing from random to quiz. ${ }^{7}$ In the public

\footnotetext{
${ }^{7}$ We call this "meritocratic attitudes" because quiz performance reflects ability or skills and resulting income differences may be regarded as justified. See, for instance, Alesina and Angeletos (2005) who point out that
} 
setting, this same level effect should be present but, in addition, individuals may want to signal that they are meritocratic, i.e. that they respect income that was earned in a competitive environment. In this case, our previous estimate of the ability-related stigma effect would be biased upwards. By comparing the observed public-private gaps in the two redistribution treatments with those in the two subsidy treatments, we can test whether individuals indeed try to signal a meritocratic attitude. More formally, meritocratic signaling can be isolated by estimating the following triple-difference (diff-in-diff-in-diff):

$$
\operatorname{DiDiD}:=\underbrace{\overbrace{\left[\left(t_{\text {priv,quiz }}-t_{\text {pub,quiz }}\right)\right.}^{\text {ability }+ \text { free-rider+meritocratic }}-\overbrace{\left(t_{\text {priv,rand }}-t_{\text {pub,rand })}\right)}^{\text {free-rider }}}_{\text {redistribution }}-\underbrace{[\overbrace{\left(t_{\text {priv,quiz }}-t_{\text {pub,quiz }}\right)}^{\text {ability }}-\left(t_{\text {priv,rand }}-t_{\text {pub,rand }}\right)]}_{\text {subsidized }} .
$$

If meritocratic signaling matters, this triple-diff should be positive:

Prediction 5 (Meritocratic signaling). The difference in the public-private gaps between quiz and random is smaller in the subsidized treatments than in the redistribution treatments: DiDiD> 0 .

Equation (1) also summarizes which kind of social signaling is active in which treatment. Since taking up a transfer reduces the income of others in the redistribution treatment, it carries a free-rider signal. In the quiz treatment, ranks are based on performance in the knowledge quiz so that take-up also reveals something about the ability of a claimant. In the quiz redistribution treatment, take-up conveys a signal about the willingness to respect income earned in a competitive environment, i.e. a meritocratic signal. The random subsidized treatment does not contain any signal and can thereby isolate potential transaction costs that might be present in all treatments.

\subsection{Procedures}

The experiments were carried out at Technical University Berlin between November 2015 and June 2016. The experimental software was programmed using z-Tree (Fischbacher, 2007) and subjects were recruited using ORSEE (Greiner, 2015). In total, 441 subjects took part in 14 sessions of 24 subjects and five sessions of 21 subjects. ${ }^{8}$ The number of sessions and subjects per treatment is summarized in Table 2. Sessions lasted 45 to 60 minutes each, with participants earning, on average, 11.24 Euros.

Upon entering the laboratory, subjects were randomly allocated a cubicle and asked to carefully read the experimental instructions for stage (1) and work on the quiz task. After the quiz had ended, participants received instructions for stages (2) and (3) of the experiment, including a set of control questions. The experiment only started once everyone had correctly answered all

whether inequality is based on luck or ability determines demand for redistribution. Experimental evidence also suggests that many people favor redistribution when inequality is due to luck but much less so when inequality results from individual choices (Cappelen et al., 2013).

${ }^{8}$ The approximate number of necessary subjects for the redistributive treatments was determined by a power analysis. The effect size used for the calculation is based on a pilot study with a similar design that one of the co-authors conducted for his Master thesis (see Schmacker, 2015). 
Table 2: Numbers of sessions and subjects per treatment

\begin{tabular}{c|cc|c}
\hline & redistribution & subsidy & Description \\
\hline quiz & $\begin{array}{c}7 \text { sessions, 165 } \\
\text { subjects }\end{array}$ & $\begin{array}{c}3 \text { sessions, 69 } \\
\text { subjects }\end{array}$ & $\begin{array}{c}\text { rank based on } \\
\text { quiz } \\
\text { performance }\end{array}$ \\
random & $\begin{array}{c}7 \text { sessions, 159 } \\
\text { subjects }\end{array}$ & $\begin{array}{c}\text { 2 sessions, 48 } \\
\text { subjects }\end{array}$ & $\begin{array}{c}\text { rank } \\
\text { determined } \\
\text { randomly }\end{array}$ \\
\hline Description & $\begin{array}{c}\text { transfer to rank 3 is } \\
\text { paid by better } \\
\text { ranked subjects }\end{array}$ & $\begin{array}{c}\text { transfer to rank 3 is } \\
\text { paid by } \\
\text { experimenter }\end{array}$ & \\
\hline
\end{tabular}

Notes: Table gives an overview over the number of subjects in each treatment. Note that each subject takes part in both the private and the public treatment.

questions. Following the experiment, we administered a post-experimental questionnaire while preparing payments. Payments were made individually in a separate room.

\section{$3 \quad$ Experimental results}

Subjects answered an average of 9.57 questions in the quiz correctly, with a minimal score of 3 , i.e., all subjects worked on the task. The quiz task differentiated well between the ranks. There was a significant difference in the number of questions correctly answered: Those in rank 1 answered 11.82 correctly, while those in rank 2 answered 9.52 correctly $(t(154)=8.375, p<0.001)$, who themselves answered more correctly than those in rank 3 with 7.44 questions $(t(154)=$ $7.859, p<0.001)$. There are no statistical differences to the random treatment with respect to the number of questions answered correctly, although in this treatment subjects were told that ranks did not depend on quiz performance. Moreover, the participants did not differ across treatments with respect to any demographic characteristic that we elicited. ${ }^{9}$

To test our hypotheses, we investigate the take-up behavior as elicited by the strategy method, meaning that the actual number of claimants is not relevant for the analysis. ${ }^{10} \mathrm{We}$ first show that public exposure significantly reduces the take-up rate of a redistributive transfer when eligibility is based on quiz performance. Having established the existence of a stigma effect, we decompose it into effects related to ability signaling and to free-rider signaling by looking at a treatment in which eligibility is based on a randomly drawn rank. Then, we present results from the subsidized treatments that allow us to separate ability and free-rider signaling from other possible explanations like meritocratic considerations and transaction costs.

\footnotetext{
${ }^{9}$ Table 6 in the Appendix displays descriptive statistics of the sample. Fifty-nine percent of subjects are male, subjects are an average of 24 years old, nearly all are students, and almost thirty percent work. Twenty-four percent are enrolled in a subject related to economics (economics, business, industrial engineering) and none had ever participated in more than three experiments.

${ }^{10}$ In 126 out of 147 groups a transfer was claimed, with 35 transfers given out under the stigma regime and 91 under the private regime. In all but two sessions there was at least one claimant who received a public transfer.
} 
Figure 1: Take-up rate by transfer regime (redistribution treatments)

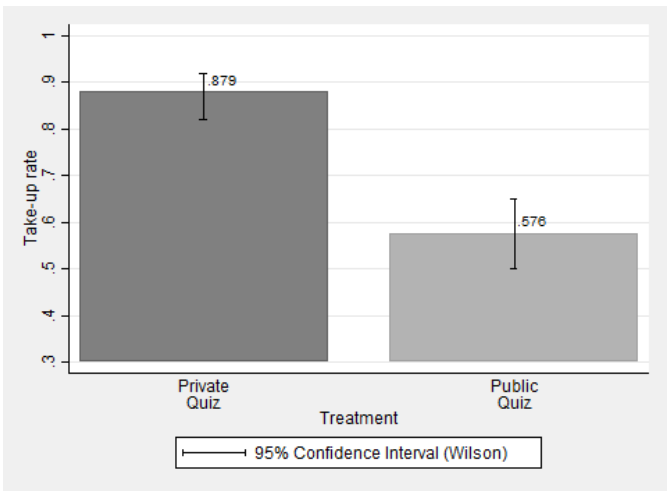

(a) quiz treatment $(\mathrm{n}=165)$.

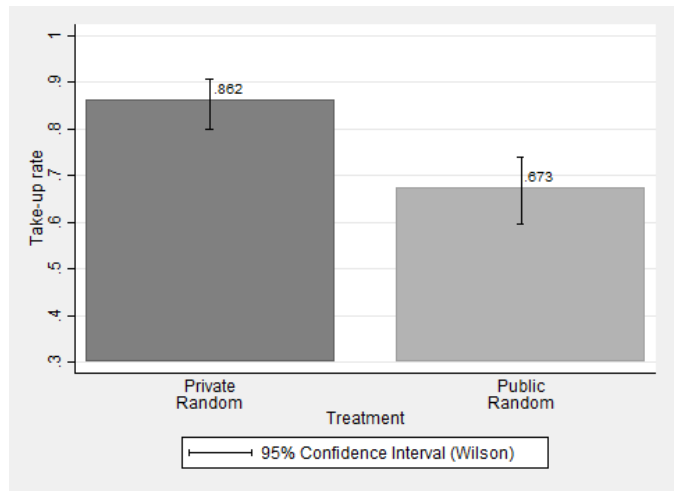

(b) random treatment $(\mathrm{n}=159)$

Notes: Plots show the fraction of subjects who take up a redistributive transfer in the respective treatment. Figure 1a shows the take-up rates in the public and private treatment if ranks are based on quiz performance, and Figure $1 \mathrm{~b}$ if ranks are determined randomly.

\subsection{Evidence of welfare stigma}

Figure 1a illustrates the take-up rates under the private and public transfer regime in the quiz redistribution treatment, in which income is based on quiz performance and transfers come at a cost to other participants. The left bar shows that 87.9 percent of subjects decide to take up the transfer if it was private, whereas only 57.6 percent would do so in the public treatment (right bar). The resulting public-private gap of 30.3 percentage points is statistically significant $(t(164)=7.998, p<0.001)$ and relevant in magnitude; the take-up rate goes down by a third. This effect is remarkable because forgoing the transfer is costly: Not taking the transfer means passing up a 50 percent increase in the experimental earnings when ranked third, i.e. taking 6 Euros instead of 9 Euros.

Recall that by comparing public and private, we net out all potential determinants that might affect the take-up behavior but that are invariant to the visibility of the welfare takeup decision. Other determinants may include, for instance, self-image concerns or internalized shame. Similarly, other psychological frictions (e.g., decision errors) that may explain why the take-up rate deviates from 100 percent, which would be the prediction of a neoclassical model of welfare take-up behavior, cannot explain the stigma effect. Under the assumption that transaction costs are not relevant, the only thing that varies is the visibility of the take-up decision. Hence, the treatment effect can only be attributed to a participant's anticipation of the inferences the public (i.e., the other participants in the laboratory) will make upon observing her taking up the transfer. This finding confirms Prediction 1.

Result 1 (Welfare Stigma/Social Signaling). The take-up rate in the quiz-redistribution treatment is significantly lower in public than in private (both statistically and economically). 


\subsection{Ability and free-rider signaling as determinants of welfare stigma}

To disentangle which signaling motive drives the observed stigma effect in take-up rates, we look at the random redistribution treatment, where a subject's rank and, therefore, also eligibility to claim a transfer is determined randomly. If the stigma effect goes to zero when transfer eligibility is random, the stigma effect described above must be driven by ability signaling alone. If we find a stigma effect of similar size, we would conclude that free-rider signaling is the only relevant factor. If it decreases but remains significantly positive, it would suggest that both ability and free-rider signaling are at play (cf. Predictions 2 and 3).

Figure $1 \mathrm{~b}$ depicts the take-up rate in the random redistribution treatment, again divided into public and private. We also observe a difference in the take-up rates when rank is assigned by chance: Here, the stigma effect amounts to 18.9 percentage points. Making the take-up of the transfer public reduces the take-up rate by roughly 22 percent from the take-up rate in private, leading to the conclusion that a concern for free-rider signaling affects the take-up decision, thus confirming Prediction 2.

Result 2 (Free-rider signaling). The take-up rate in the random-redistribution treatment is significantly lower in public than in private.

However, the stigma effect is smaller if income is determined randomly (0.189) than if it is based on the quiz (0.303). To statistically test for differences between random and quiz, we estimate the following model

$$
\text { Take-up }_{i}=\alpha+\beta_{1} \text { Quiz }_{i}+\beta_{2} \text { Public }_{i}+\beta_{3}(\text { Quiz x Public })_{i}+\epsilon_{i},
$$

using ordinary least squares with standard errors clustered on the subject level. The estimated interaction effect $\beta_{3}$ and its standard error are reported in the bottom-right cell in Table $3 .{ }^{11}$ As can be seen, the diff-in-diff of 0.114 is significant at the 5 percent level, suggesting that ability signaling does indeed matter. This finding supports our Prediction 3.

Result 3 (Ability signaling). The stigma effect is significantly higher in the quiz-redistribution treatment than in the random-redistribution treatment.

Table 3 summarizes the take-up rates of the treatments discussed so far and the estimated differences between them. Note that when the transfer is private, we find virtually no difference in the take-up rates between quiz and random (first column of Table 3). This result is consistent with the notion that there is no room for social image concerns in the private treatment. This zero difference in take-up rates between quiz and random in the private treatment also indicates that individuals do not act as if they perceive it to be more morally appropriate to claim a transfer if income is based on luck than if it is based on performance. ${ }^{12}$ In contrast, in the

\footnotetext{
${ }^{11}$ The complete regression results of equation (2), also controlling for age, gender and the share of male subjects in a session, are presented in columns 1 and 2 in table 7 in the appendix.

${ }^{12}$ Behavior appears to differ from stated attitudes in this case: In our post-experimental questionnaire, we find some indication for this kind of meritocratic attitudes. Subjects in the quiz treatment agree to the statement "The subject in rank three is entitled to receive a transfer" to a significantly lower degree than in the random treatment according to a Wilcoxon rank-sum test $(z=4.435, p<0.001)$. The difference in perceived entitlement may just not be large enough to affect behavior.
} 
Table 3: Take-up rates in respective treatment (redistribution)

\begin{tabular}{lcc|c}
\hline Task & Private transfer & Public transfer & Difference (paired) \\
\hline Quiz & 0.879 & 0.576 & $0.303^{* * *}$ \\
& $(0.025)$ & $(0.039)$ & $(0.038)$ \\
Random & {$[165]$} & {$[165]$} & {$[165]$} \\
& 0.862 & 0.673 & $0.189^{* * *}$ \\
& $(0.027)$ & $(0.037)$ & $(0.032)$ \\
\hline Difference & {$[159]$} & {$[159]$} & {$[159]$} \\
(unpaired) & 0.017 & $-0.097^{*}$ & DiD $=0.114^{* *}$ \\
& {$[0.037)$} & $(0.054)$ & $(0.050)$ \\
& {$[324]$} & {$[324]$} & {$[324]$} \\
\hline
\end{tabular}

Notes: Table shows the fraction of subjects who take up a redistributive transfer in the respective treatment. The difference column gives paired t-test results of the $\mathrm{H} 0$ that there is no difference between private and public take-up in the respective treatment. The difference row shows unpaired t-test results of the H0 that there is no difference in private and public take-up between quiz and random treatment. The bottom right cell is the difference in difference estimate between row and column difference. It amounts to estimating equation (2) with standard errors clustered on subject level. Standard errors are in parentheses and number of observations in square brackets. ${ }^{*} p<0.10,{ }^{* *} p<0.05,{ }^{* * *} p<0.01$

public treatment, the take-up rate is 9.7 percentage points lower when ranks are based on quiz rather than on luck (a decrease of 14.4 percent in the take-up rate), implying that the estimated diff-in-diff effect is indeed largely driven by behavioral adjustments under the visibility of welfare transfers.

\subsection{Excluding transactions costs and meritocratic signaling as confounds}

We argue that our experimental design can identify and disentangle free-rider and ability signaling as components of the total stigma effect. Our argument relies on two assumptions that are tested in this section. (1) We assume that transactions costs are not relevant, which implies that the stigma effect in the random redistribution treatment identifies free-rider signaling. (2) We assume that free-rider signaling concerns do not vary between the random and the quiz treatment, which ensures that the interaction effect between quiz treatment and public take-up measures ability signaling. The first assumption is violated if participants experience transaction costs in the public setting, for instance because they dislike having to stand up and walk to the experimenter's desk. The second assumption is violated if individuals want to signal a meritocratic attitude, i.e. they want to signal that they find it more objectionable to take money from other group members when income is based on performance than when it is based on luck. The desire to signal a meritocratic attitude could also result in the non-zero diff-in-diff that we have ascribed to ability signaling above and it would bias our estimate of the stigma effect upwards.

We test these two assumptions using the subsidized treatment, where taking up the transfer does not affect the earned incomes of others. First, we test whether transaction costs are relevant (cf. Prediction 4) by comparing take-up rates between private and public when ranks are random so that both ability and free-rider signaling are ineffective. Second, we test whether 
Figure 2: Take-up rate by transfer regime (subsidized treatments)

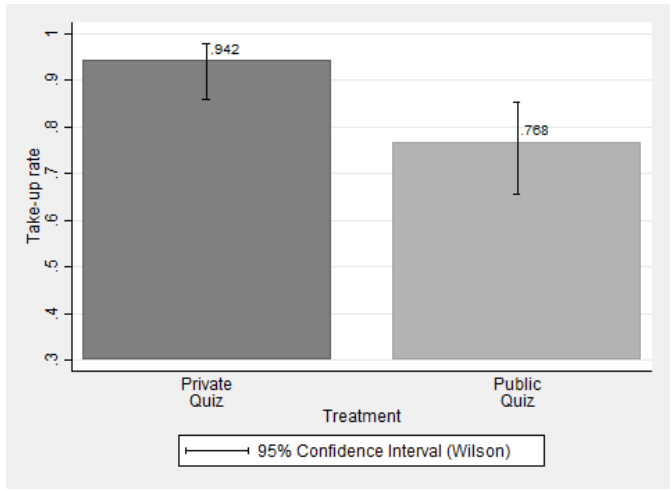

(a) quiz treatment $(\mathrm{n}=69)$

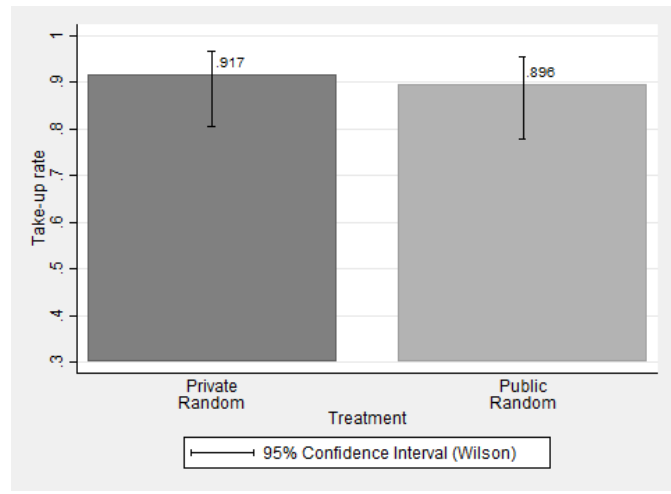

(b) random treatment $(\mathrm{n}=48)$

Notes: Plots show the fraction of subjects who take up a non-redistributive (subsidized) transfer in the respective treatment. Figure $2 \mathrm{a}$ shows the take-up rates in the public and private treatment if ranks are based on quiz performance, and Figure $2 \mathrm{~b}$ if ranks are determined randomly.

meritocratic signaling plays a role (cf. Prediction 5) by comparing the diff-in-diffs between redistribution and subsidy treatments.

Figure 2 and Table 4 summarize the results of the subsidized treatments. ${ }^{13}$ The random treatment reported in the second row of Table 4 shuts down the ability signaling channel but captures any other factors that would produce a positive public-private gap. As shown, the public-private gap vanishes almost completely. While the point estimate of 0.021 is still positive, it is not statistically different from zero at conventional statistical levels. More specifically, the observed point estimate would only become significant in a test with power of 0.8 when the sample had more than 3,700 observations, suggesting that the public setting does not generate transaction costs at a relevant level (cf. Prediction 4). This observation is reassuring as it suggests that the observed stigma effect is, in fact, driven by social image concerns.

Result 4 (Placebo test). In the subsidized random treatment, public take-up is not significantly different from private take-up.

We also find that the desire to signal a meritocratic attitude does not have a significant effect on take-up rates. When we difference the two public-private gaps of the subsidized treatments, we obtain an estimate of the stigma effect due to ability signaling of 0.153 , which is slightly higher than the estimate of 0.114 obtained from the redistribution treatments in the previous section. To test for statistical differences between the two diff-in-diffs, we pool the observations from all treatments presented so far and estimate the following model:

(3) Public-private gap $_{i}=\alpha+\beta_{1}$ Quiz $_{i}+\beta_{2}$ Redistribution $_{i}+\beta_{3}(\text { Quiz x Redistribution })_{i}+\epsilon_{i}$,

\footnotetext{
${ }^{13}$ Regression results, also controlling for age, gender and the share of male subjects in a session are found in column 4 of table 7 in the appendix.
} 
Table 4: Take-up rates in respective treatment (subsidized)

\begin{tabular}{lcc|c}
\hline Task & Private transfer & Public transfer & Difference (paired) \\
\hline Quiz & 0.942 & 0.768 & $0.174^{* * *}$ \\
& $(0.028)$ & $(0.051)$ & $(0.054)$ \\
Random & {$[69]$} & {$[69]$} & {$[69]$} \\
& 0.917 & 0.896 & 0.021 \\
& $(0.040)$ & $(0.045)$ & $(0.047)$ \\
\hline Difference & {$[48]$} & {$[48]$} & {$[48]$} \\
(unpaired) & 0.025 & $-0.128^{*}$ & $\mathrm{DiD}_{\mathrm{s}}=0.153^{* *}$ \\
& $(0.048)$ & $(0.071)$ & $(0.076)$ \\
\hline
\end{tabular}

Notes: Table shows the fraction of subjects who take up a non-redistributive (subsidized) transfer in the respective treatment. The difference column gives paired t-test results of the $\mathrm{H} 0$ that there is no difference between private and public take-up in the respective treatment. The difference row shows unpaired t-test results of the H0 that there is no difference in private and public take-up between quiz and random treatment. The bottom right cell is the difference in difference estimate between row and column difference. Standard errors are in parentheses and number of observations in square brackets. ${ }^{*} p<0.10,{ }^{* *} p<0.05,{ }^{* * *} p<0.01$

where we regress the public-private gap, i.e., the within-subject difference $\left(t_{\text {pub }}-t_{\text {priv }}\right)$ between the public and the private transfer regime, on treatment dummies for quiz and redistribution and their interaction. The interaction coefficient $\beta_{3}$ identifies the meritocratic component.

The output of model 3 is presented in Table 5 . As shown, the estimate of $\beta_{3}$ is insignificant, suggesting that there is not a significant difference between the two differences. In a test with power 0.8 , the estimated effect would only become significant in a sample with more than 3,800 observations. Therefore, our data does not support the hypothesis underlying Prediction 5 that individuals want to appear as if they honored earned income more than random income.

Result 5 (No meritocratic signaling). The difference in public-private gaps between quiz and random are not significantly different between subsidized and redistribution treatment (i.e. the DiDiD estimator is not significant).

This result implies that the ability effect estimated in our previous section is not driven by signaling meritocratic considerations. In fact, $\beta_{1}$ estimates an ability signaling effect of 0.153 net of potential interactions with free-rider signaling as well as transaction costs. Moreover, $\beta_{2}$, estimated to 0.168 , identifies the free-rider signaling effect, net of potential transaction costs.

While we are not interested in the absolute level of take-up but only in treatment differences, we note that almost everyone claimed the transfer in private in the subsidized treatments. This result indicates that the vast majority of participants feels that taking money from the experimenter is acceptable, so that it is unlikely that free-rider stigma plays any role in the subsidized treatments. In principle, there may still be some subjects who are reluctant to take money from the experimenter and experience stigma when doing so publicly. By construction of our experiment such experimenter-related free-rider stigma would be part of the transaction cost component, which is not significantly different from zero as discussed above. 
Table 5: Regression of the public-private gap on treatment dummies

\begin{tabular}{lc}
\hline & public-private gap \\
\hline Quiz & $0.153^{* *}$ \\
& $(0.072)$ \\
Redistribution & $0.168^{* * *}$ \\
& $(0.057)$ \\
Quiz x Redistribution & -0.039 \\
& $(0.087)$ \\
Constant & 0.021 \\
& $(0.047)$ \\
\hline Adj. R2 & 0.031 \\
N & 441
\end{tabular}

Notes: Table shows OLS regression results of equation (3) with standard errors clustered on subject level. We regress the individual public-private gap, i.e. the within-subject difference between private and public take-up, on treatment dummies. The treatment dummies indicate whether or not the transfer is redistributive (redistribution) and whether or not income is based on quiz performance (quiz). The interaction between the two measures the public-private gap when the transfer is both redistributive and based on quiz performance. The constant measures the public-private gap when ranks are randomly assigned and the transfer is subsidized by the experimenter. ${ }^{*}$ $p<0.10,{ }^{* *} p<0.05,{ }^{* * *} p<0.01$

\subsection{No evidence for heterogenous treatment effects}

In this section, we investigate whether the stigma effect in our main treatment (quiz and redistribution) varies systematically across subgroups. We focus on subgroups that are more or less likely to become welfare recipients in real life and assess the robustness of our results in these different subsamples.

If performance in the quiz is seen as a proxy for ability in real life, those subjects who perform worst in the quiz can be considered as the most vulnerable subgroup. If the stigma effect is only relevant for those subjects who perform well but are not likely to become welfare claimants in real-life, the external validity for real-life welfare systems would be limited. However, we find that the stigma effect persists without systematic differences in all ability groups, giving us confidence that the stigma effect is a robust finding that is also relevant for more vulnerable groups. Figure 5 in the appendix illustrates this finding by showing take-up rates in public and private by terciles of the quiz performance distribution.

Since our sample consists predominantly of students, we further argue that those subjects who work besides their studies, supposedly to earn their living, are a more vulnerable group in terms of socioeconomic background than those who do not work. If the stigma effect would not show up in this subgroup, doubts about the external validity could arise. We find that, if anything, the stigma effect is stronger for the working subsample (see Figure 6 in the appendix showing the take-up rates by working status), but that difference is far from significant.

Finally, we look for heterogenous stigma effects by gender. We observe that female subjects take up an anonymous transfer slightly more often than males but the stigma effect is not significantly different between males and females (see Figure 7 in the appendix). If we regress the public-private gap on gender, the share of male subjects in a session and its interaction, we observe that the stigma effect for females becomes significantly stronger, the smaller the share 
Figure 3: Take-up rate by expected rank $(\mathrm{n}=234)$

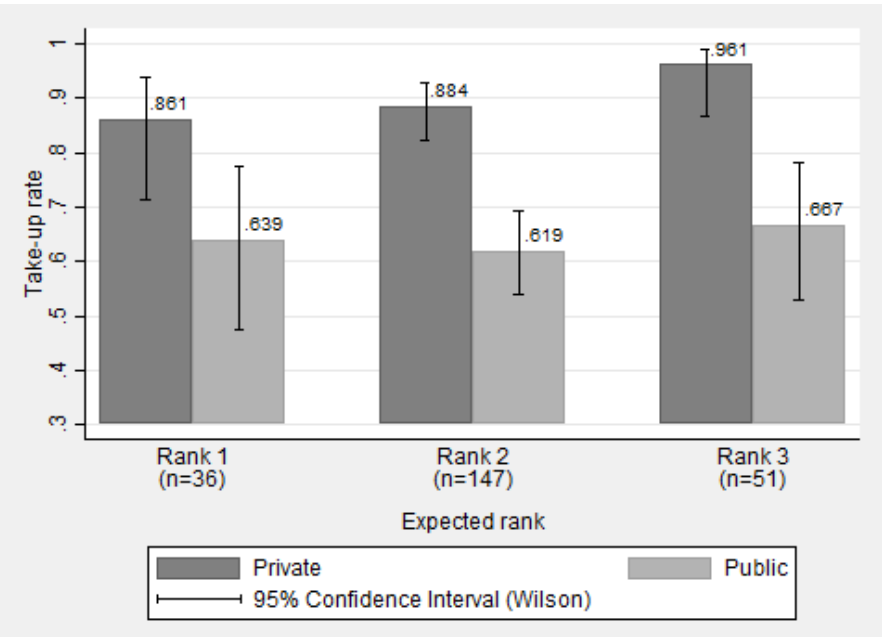

Notes: Plot shows the take-up rate in the public and private treatment conditional on the rank in which subjects expect to be after answering the quiz. We only consider subjects in the quiz treatment since the quiz is not incentivized in the random treatment. There are no significant differences in take-up between expected ranks in either the public or private treatment.

of male subjects in the session. In contrast, the stigma effect of male subjects does not seem to react to the share of male subjects in the session. However, as our experiment is not designed for testing gender effects we leave this as a venue for further research.

\subsection{Robustness: Experimenter demand effect and strategy method}

First, we show that the results are unlikely to be driven by an experimenter demand effect, which one could be concerned about due to the within-subject design using the strategy method. As subjects are asked to make their take-up decision for both the public and the private transfer regimes, they might feel inclined to give systematically different responses across settings, thereby producing an artificial public-private gap in take-up rates. We mitigate such tendencies by not presenting both transfer regimes at the same time; rather these are shown in randomized order on separate screens. When subjects are asked about their take-up decision for the private transfer, they do not know that there will also be a decision for a public transfer, and vice versa. If there was an experimenter-demand effect, we would expect that subjects who learn on the second screen that there is both a public and a private transfer have lower public take-up rates when private is presented first and higher private take-up rates when public is presented first. Instead, we observe that pooled over all treatments the mean take-up rate of the public (private) transfer is $0.675(0.886)$ if the private transfer is presented first and 0.677 (0.887) if the public transfer is presented first. Thus, there are no systematic differences in line with an experimenter demand effect. Similarly, there are no significant differences in the take-up rates when comparing order effects by treatment. A different type of demand effect where individuals respond feeling pressured to answer consistently across public and private conditions would only work against finding a stigma effect. 
Second, we check whether the take-up decision is associated with the expectation about one's own rank when income is based on quiz performance. If the stigma effect is different between those who are confident being in rank 1 and those who suspect they are in rank 3, the strategy method might not be appropriate. Therefore, it is reassuring that there are no significant differences in the take-up by expected rank as Figure 3 illustrates.

Third, we provide evidence that our treatments actually result in measurable variations in the perceived extent of ability signaling. A Wilcoxon rank-sum test reveals that there is greater approval to the statement "The participant in rank 3 has poor knowledge" in the quiz treatment than in the random treatment $(z=-8.706, p<0.001)$. Moreover, significantly more subjects in the random treatment believe that the person in rank 3 had bad luck $(z=5.292, p<0.001)$. Thus, the survey answers support our identification of ability signaling, which rests on the assumption that subjects perceive taking up a transfer in the quiz treatment as sending a negative signal about their ability. However, there are still many subjects who consider quiz performance to be a matter of luck (see Table 8 in the appendix). Thus, we conclude that our experimental measure of ability-related welfare stigma represents a lower bound of this effect. The survey answers suggest that an income source that is more strongly associated with ability (e.g., IQ test, school grades) might produce an even larger stigma effect.

\section{Preferences for transfer regime}

So far, we analyzed how stigmatization affects individual decisions to take up a welfare transfer. In this section, we present results from the second part of our experiment, where we use a random dictator decision rule to elicit individuals' preferences for the public or private transfer mode.

Figure 4 illustrates the fraction of participants who vote in favor of the public transfer regime, divided by rank and income source. As subjects already know their rank at this stage, we differentiate between those who presumably benefit from the public transfer regime (ranks 1 and 2) because it reduces take-up and those who are harmed by it due to stigmatization (rank 3 ). As expected, few subjects in rank 3 vote in favor of the public transfer regime, and, across all treatments, they are less likely to vote for the public regime than those in ranks 1 and 2 .

However, keeping in mind that the take-up rate is much lower under the public transfer regime, it is striking that there are relatively few rank 1 and rank 2 subjects voting for it. If we assume that subjects take the stigma effect into account - and we find a strong indication that they do in the post-experimental questionnaire ${ }^{14}$ - we would expect all payoff-maximizing agents in rank 1 and 2 to vote in favor of the public transfer, which is clearly not the case. Moreover, Figure 4 shows that there are more subjects in rank 1 who vote for the public transfer regime in the quiz treatment, although none of the treatment differences are significant. ${ }^{15}$

\footnotetext{
${ }^{14} 75.3$ percent of subjects on rank 1 and 2 agree to the statement "It is discomforting for the claimant when the transfer is public" and 70.8 percent agree to the statement "Public transfers reduce take-up probability."

${ }^{15}$ One reason why the support for the public transfer mode is higher in the quiz than in the random treatment could be that participants are curious about who performed poorly in the quiz and are not ashamed of admitting so and of asking for redistribution. If this was the case, it would only add to the neoclassical motives for voting in favor of the public transfer and cannot explain why support for the public regime is so low.
} 
Figure 4: Share voting for public transfer by rank and task, only redistribution $(\mathrm{n}=324)$

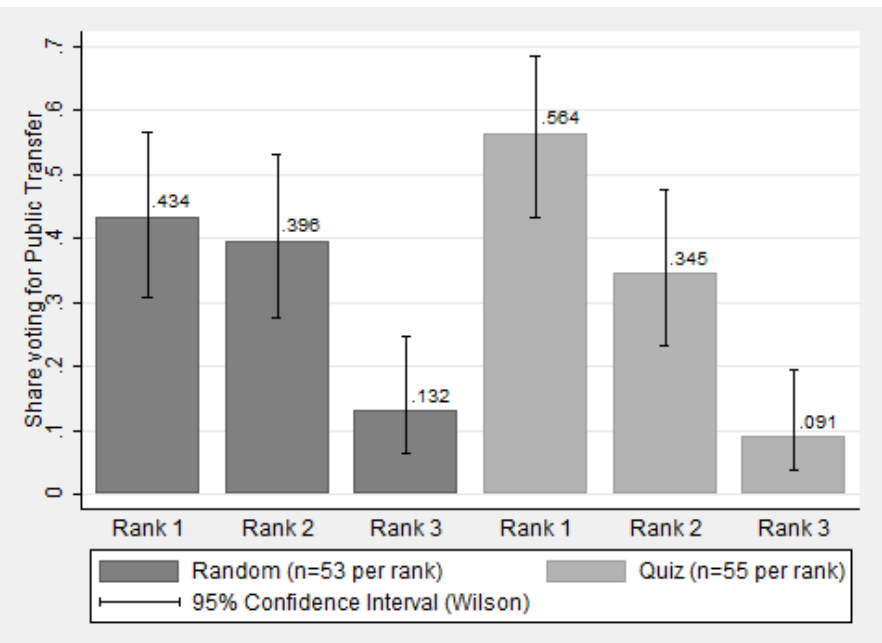

Notes: Plot shows the share of subjects who vote for the public transfer depending on rank and treatment. We exclude the subsidized treatments since there the transfer does not affect the payoff of subjects in rank 1 and 2 .

In order to investigate the reasons for the voting pattern of the net payers, Table 9 in the appendix takes a closer look at the voting motives that were stated by the subjects in the post-experimental questionnaire. We see that a majority of subjects in ranks 1 and 2 who voted for the public transfer agreed to the statement "I want to reduce the take-up probability to raise my payout." However, they are rather indifferent to the statement "Free-riders should be identified as such." In contrast, 82.0 percent of those who voted against the public transfer agreed to the statement "I don't want the claimant to be ashamed." Thus, there are, on the one hand, many subjects who anticipate the existence of a stigma effect and vote for the public transfer to reduce the take-up probability. On the other hand, many subjects acknowledge the existence of welfare stigma but have social preferences toward the subject in rank 3 . They vote against the public transfer to spare them the shame of stigmatization. ${ }^{16}$

In summary, the voting patterns from the second part of the experiment provide further evidence of the existence of welfare stigma in line with our intuition and the theoretical framework in the appendix. These findings indicate that we should not only investigate preferences for redistribution, but we need to take into account that individuals have preferences with respect to the way that redistributive payments are paid out. Specifically, our data suggests that even many of those individuals who are net payers dislike stigmatization.

\section{Concluding Discussion}

Economists typically believe that the welfare take-up decision of individuals is driven by the trade-off between the costs and benefits of claiming a welfare transfer and possibly subject to mistakes due to inattention or incomplete information. Using a laboratory experiment,

\footnotetext{
${ }^{16}$ Nevertheless, there are a few subjects who appear not to be responsive to stigma. Among those who are in rank 3 and vote in favor of the public transfer regime, 6 out of 11 disagree with the statement "It is discomforting for the claimant when the transfer is public."
} 
our paper provides first causal evidence that social image concerns, forming part of the costs associated with claiming a transfer, systematically affect an individual's decision to take up a social transfer. We show that our subjects are more reluctant to take up a redistributive transfer when claiming is publicly observable; and even more so when the take-up decision is informative about the claimants' ability. In doing so, the subjects forgo a considerable increase in payoffs.

Our results contribute to several aspects of the literature on welfare stigma and take-up. First, our results suggest that individuals might intentionally decide to not apply for public assistance, even though they are fully aware of its existence and features. Our experimental findings, thereby, complement existing research showing that unawareness, misperceptions, and inattention contribute to low take-up rates without fully explaining them (see, e.g., Finkelstein and Notowidigdo, 2018). Second, our findings shed light on the distinction between social stigma as the anticipation of a negative social image (Bursztyn and Jensen, 2017) and personal stigma (as targeted by the intervention of Bhargava and Manoli, 2015). In our lab experiment, we only find evidence of social stigma: While individuals condition their take-up decision on the possibility of social inferences, take-up is not decreased when feelings of legitimacy are varied keeping the take-up decision private. Third, the finding that individuals care about whether others perceive them as social free-riders suggests that stigmatization may also contribute to low take-up rates in programs that do not condition eligibility on individual economic performance. This is in contrast to Currie (2006), who refers to incomplete take-up in non-means-tested welfare programs as evidence against the stigma hypothesis, because take-up in these programs does not signal anything about claimants' earnings opportunities or wealth.

Our findings have a number of potential implications for the design and organization of welfare programs. If the policy maker aims to achieve complete take-up by the target group, our results suggest that social welfare services should be provided as anonymously as possible, and that increased anonymity can be effective also in non-means-tested programs, where social stigma is typically neglected. ${ }^{17}$ On the one hand, the results imply that the process of claiming a transfer should, to the extent possible, protect the privacy of the claimant. For instance, the use of online forms could reduce the amount of personal contact with officials. Further, waiting rooms could pool individuals with different types of requests (e.g., claiming welfare benefits, getting a new passport, registering a newborn) such that the mere presence in the room does not allow for inferring an individual's reason for being there. On the other hand, our results apply to the delivery of social benefits. In particular, social image concerns may provide an argument for cash rather than in-kind transfers because the former are typically less visible and, therefore, less prone to welfare stigma than the latter. Moreover, indispensable in-kind benefits should be delivered such that it is difficult to identify claimants. For instance, social housing should be dispersed across (better-off) neighborhoods and school catering systems should use cashless payment to avoid identification of the welfare recipients. If, in contrast, the policy goal

\footnotetext{
${ }^{17}$ Improving the take-up of social programs is a common policy objective because the effectiveness of a welfare program depends on it reaching its target group. For example, the European Commission (2015, p. 3) refers to the need to reduce non-take-up in its proposed Council Decision on guidelines for the employment policies of the Member States: "Social protection systems should be designed in a way that facilitate take up of all persons entitled, support investment in human capital, and help prevent, reduce and protect against poverty."
} 
is to reduce the take-up rate of a program, social transfers should be made less anonymous. In addition, our result that social, and not personal, stigma affects take-up implies that policy interventions targeting personal beliefs about the legitimacy of take-up (as in Bhargava and Manoli, 2015) might be ineffective if the visibility of the take-up decisions is unchanged.

An experimental approach to welfare take-up has the advantage that it allows us to draw causal inferences and to disentangle the effect of social image concerns from other relevant factors. But, as with every lab experiment, questions of external validity naturally arise. In particular, one might argue that our subject pool, which consists mostly of university students, does not represent a relevant population for the study of welfare take-up because welfare programs are predominantly designed for at-risk populations. However, students typically do not receive high market incomes while they study. ${ }^{18}$ Moreover, in many countries, such as in Germany, where our experiment took place, many university students receive highly subsidized and means-tested student loans that depend on the size of their parents' income. Hence, a substantial fraction of the student population has experience with welfare programs. Therefore, our paper shows the existence of welfare stigma effects in a relevant social group. Also note that our stigma treatment is quite weak. Being ranked third in a general knowledge quiz in a randomly selected group of three students is supposedly not overly stigmatizing. Nevertheless, we find a strong behavioral effect of making social transfers public in this setting. The effect persists across all meaningful subgroups, especially for those who can be considered the most vulnerable individuals in our sample, like those who are, in addition to their studies, working or those who perform worst in the knowledge quiz. Thus, we are confident that our findings are not a peculiarity of the specific subject pool we use, but that social stigma effects at least qualitatively persist outside the lab even though the situation there differs from the specific setup in the lab. Future field experiments can build on our lab findings in order to assess the quantitative importance of welfare stigma in real-world take-up decisions, noting that the relative importance of welfare stigma and other barriers to take-up may well depend on the specific welfare program under consideration.

Our design deliberately abstracts from several interesting aspects that are also relevant for program participation outside the lab. For instance, individuals typically choose how much to work or shirk, and eligibility not only depends on ability but also on endogenously chosen effort levels. The desire to avoid stigmatization associated with being on welfare may lead individuals to choose higher effort levels in the first place. Therefore, reducing the cost associated with claiming a transfer by reducing its stigmatization may also lead some individuals to reduce their effort levels in order to become eligible (Kline and Tartari, 2016; Hartley and Lamarche, 2017). Furthermore, as some individuals may falsely claim a transfer they are not eligible for, stigmatization may deter some of these unjustified claims (cf. Blumkin et al., 2015). These aspects as well as the interaction between social image concerns and other barriers to program participation are topics needing further research.

\footnotetext{
${ }^{18}$ In Germany, students at public universities, like our subjects, receive state-financed education without paying (large amounts of) taxes. They are net beneficiaries of the social system.
} 


\section{References}

Agranov, M. and Palfrey, T. R. (2015). Equilibrium tax rates and income redistribution: A laboratory study. Journal of Public Economics, 130, 45-58.

Alesina, A. and Angeletos, G.-M. (2005). Fairness and redistribution. American Economic Review, 95 (4), 960-980.

Andrade, C. (2002). The economics of welfare participation and welfare stigma: A review. Public Finance and Management, 2 (2), 294-333.

Andreoni, J. and Bernheim, B. D. (2009). Social image and the 50-50 norm: A theoretical and experimental analysis of audience effects. Econometrica, 77 (5), 1607-1636.

Ariely, D., Bracha, A. and Meier, S. (2009). Doing good or doing well? Image motivation and monetary incentives in behaving prosocially. American Economic Review, 99 (1), 544-55.

Bagwell, L. S. and Bernheim, B. D. (1996). Veblen effects in a theory of conspicuous consumption. American Economic Review, 86 (3), 349-373.

BAumberg, B. (2016). The stigma of claiming benefits: A quantitative study. Journal of Social Policy, 45 (2), 181-199.

Bénabou, R. and Tirole, J. (2006). Incentives and prosocial behavior. American Economic Review, 96 (5), 1652-1678.

Besley, T. and Conte, S. (1992). Understanding welfare stigma: Taxpayer resentment and statistical discrimination. Journal of Public Economics, 48 (2), 165-183.

Bhargava, S. and Manoli, D. (2015). Psychological frictions and the incomplete take-up of social benefits: Evidence from an IRS field experiment. American Economic Review, 105 (11), 3489-3529.

Bhatia, R., Jones, P. and Reicker, Z. (2011). Competitive foods, discrimination, and participation in the national school lunch program. American Journal of Public Health, 101 (8), $1380-1386$.

Blank, R. M. and Ruggles, P. (1996). When do women use AFDC and food stamps? The dynamics of eligibility vs. participation. Journal of Human Resources, 31 (1), 57-89.

Blumkin, T., Margalioth, Y. and Sadka, E. (2015). Welfare stigma re-examined. Journal of Public Economic Theory, 17 (6), 874-886.

Blundell, R., Fry, V. and Walker, I. (1988). Modelling the take-up of means-tested benefits: The case of housing benefits in the United Kingdom. The Economic Journal, 98 (390), $58-74$.

Bracha, A. and Vesterlund, L. (2017). Mixed signals: Charity reporting when donations signal generosity and income. Games and Economic Behavior, 104, 24-42. 
Bruckmeier, K. and Wiemers, J. (2012). A new targeting: A new take-up? Non-take-up of social assistance in Germany after social policy reforms. Empirical Economics, 43 (2), $565-580$.

- and - (2017). Benefit take-up and labor supply incentives of interdependent means-tested benefit programs for low-income households. Comparative Economic Studies, pp. 1-22.

Bursztyn, L., Ederer, F., Ferman, B. and Yuchtman, N. (2014). Understanding mechanisms underlying peer effects: Evidence from a field experiment on financial decisions. Econometrica, 82 (4), 1273-1301.

-, Egorov, G. and Jensen, R. (2018). Cool to be smart or smart to be cool? Understanding peer pressure in education. The Review of Economic Studies, forthcoming.

- and Jensen, R. (2017). Social image and economic behavior in the field: Identifying, understanding and shaping social pressure. Annual Review of Economics, 9, 131-153.

Cappelen, A. W., Konow, J., Sørensen, E. Ø. and Tungodden, B. (2013). Just luck: An experimental study of risk-taking and fairness. American Economic Review, 103 (4), 1398-1413.

Charles, K. K., Hurst, E. and Roussanov, N. (2009). Conspicuous consumption and race. Quarterly Journal of Economics, 124 (2), 425-467.

Corneo, G. and Jeanne, O. (1997). Conspicuous consumption, snobbism and conformism. Journal of Public Economics, 66 (1), 55 - 71.

Currie, J. (2000). Do children of immigrants make differential use of public health insurance? In G. J. Borjas (ed.), Issues in the Economics of Immigration, University of Chicago Press for NBER, pp. 271-308.

- (2006). The take-up of social benefits. In A. Auerbach, D. Card and J. Quigley (eds.), Poverty, the Distribution of Income, and Public Policy, New York: Russell Sage, pp. 80-148.

DellaVigna, S., List, J. A., Malmendier, U. and RaO, G. (2017). Voting to tell others. Review of Economic Studies, 84 (1), 143-181.

Department of Work And Pensions (2016). Income-related benefits: Estimates of take-up: Financial year 2014/15. https://www.gov.uk/government/statistics/ income-related-benefits-estimates-of-take-up-financial-year-201415 $(14 / 06 / 2017)$.

Durante, R., Putterman, L. and van der Weele, J. (2014). Preferences for redistribution and perception of fairness: An experimental study. Journal of the European Economic Association, 12 (4), 1059-1086.

Eriksson, T., Mao, L. and Villeval, M. C. (2017). Saving face and group identity. Experimental Economics, 20 (3), 622-647. 
Eurofound (2015). Access to social benefits: Reducing non-take-up. Publications Office of the European Union, Luxembourg.

European Commission (2015). Proposal for a Council decision on guidelines for the employment policies of the Member States, $\operatorname{COM}(2015) 98$ final. Annex 1. http://eur-lex . europa. eu/legal-content/EN/TXT/PDF/?uri=CELEX:52015PC0098 (31/05/2017).

Ewers, M. and Zimmermann, F. (2015). Image and misreporting. Journal of the European Economic Association, 13 (2), 363-380.

Finkelstein, A. and Notowidigdo, M. (2018). Take-up and targeting: Experimental evidence from SNAP. NBER Working Paper Series, 24652.

FischBACHER, U. (2007). z-tree: Zurich toolbox for ready-made economic experiments. Experimental Economics, 10 (2), 171-178.

Friedrichsen, J. and Engelmann, D. (2018). Who cares about social image?, CRC TRR190 Discussion Paper No. 61, Collaborative Research Center Transregio 190, Munich/Berlin.

Glazer, A. and Konrad, K. A. (1996). A signaling explanation for charity. American Economic Review, 86 (4), 1019-1028.

Goffman, E. (1959). The Presentation of Self in Everyday Life. New York: Doubleday.

Gradwohl, R. and Smorodinsky, R. (2017). Perception games and privacy. Games and Economic Behavior, 104, 293-308.

Greiner, B. (2015). Subject pool recruitment procedures: Organizing experiments with ORSEE. Journal of the Economic Science Association, 1 (1), 114-125.

Haider, S. J., Jacknowitz, A. and Schoeni, R. F. (2003). Food stamps and the elderly: Why is participation so low? Journal of Human Resources, 38, 1080-1111.

Hartley, R. P. and Lamarche, C. (2017). Behavioral responses and welfare reform: Evidence from a randomized experiment. IZA Discussion Paper No. 10905, IZA-Institute of Labor Economics, Bonn, July 2017.

HefFetz, O. (2011). A test of conspicuous consumption: Visibility and income elasticities. The Review of Economics and Statistics, 93 (4), 1101-1117.

Kleven, H. J. and Kopczuk, W. (2011). Transfer program complexity and the take-up of social benefits. American Economic Journal: Economic Policy, 3 (1), 54-90.

Kline, P. and Tartari, M. (2016). Bounding the labor supply responses to a randomized welfare experiment: A revealed preference approach. American Economic Review, 106 (4), $972-1014$.

Liebman, J. B. and Luttmer, E. F. P. (2015). Would people behave differently if they better understood social security? Evidence from a field experiment. American Economic Journal: Economic Policy, 7 (1), 275-299. 
LindBeck, A., Nyberg, S. and Weibull, J. W. (1999). Social norms and economic incentives in the welfare state. Quarterly Journal of Economics, 114 (1), 1-35.

Madrian, B. C. and Shea, D. F. (2001). The power of suggestion: Inertia in 401(k) participation and savings behavior. Quarterly Journal of Economics, 116 (4), 1149-1187.

Mas, A. and Moretti, E. (2009). Peers at work. American Economic Review, 99 (1), 112-145.

McManus, T. C. and RaO, J. M. (2015). Signaling smarts? Revealed preferences for self and social perceptions of intelligence. Journal of Economic Behavior \& Organization, 110, $106-118$.

Moffitt, R. (1983). An economic model of welfare stigma. American Economic Review, 73 (5), $1023-1035$.

Perez-Truglia, R. and Cruces, G. (2017). Partisan interactions: Evidence from a field experiment in the United States. Journal of Political Economy, 125 (4).

Pinard, C. A., Bertmann, F. M. W., Byker Shanks, C., Schober, D. J., Smith, T. M., Carpenter, L. C. and Yaroch, A. L. (2017). What factors influence SNAP participation? Literature reflecting enrollment in food assistance programs from a social and behavioral science perspective. Journal of Hunger \& Environmental Nutrition, 12 (2), 151-168.

Rainwater, L. (1982). Stigma in income-tested programs. In I. Garfinkel (ed.), Income-Tested Transfer Programs, London: Academic Press, pp. 19-46.

Rege, M. and Telle, K. (2004). The impact of social approval and framing on cooperation in public good situations. Journal of Public Economics, 88 (7-8), 1625-1644.

Schmacker, R. (2015). Welfare stigma, welfare take-up and voting: An experimental investigation, Master thesis, Humboldt-Universität zu Berlin.

Sexton, S. E. and Sexton, A. L. (2014). Conspicuous conservation: The Prius halo and willingness to pay for environmental bona fides. Journal of Environmental Economics and Management, 67 (3), 303-317.

Soetevent, A. R. (2011). Payment choice, image motivation and contributions to charity: Evidence from a field experiment. American Economic Journal: Economic Policy, 3 (1), 180-205.

Sommers, B. D. and Epstein, A. M. (2010). Medicaid expansion: The soft underbelly of health care reform? New England Journal of Medicine, 363 (22), 2085-2087.

Spence, A. M. (1973). Job market signaling. Quarterly Journal of Economics, 87 (3), 355-74.

Stuber, J. and Schlesinger, M. (2006). Sources of stigma for means-tested government programs. Social Science $\& 3$ Medicine, 63 (4), 933-945.

Tyran, J.-R. and Sausgruber, R. (2006). A little fairness may induce a lot of redistribution in democracy. European Economic Review, 50 (2), 469-485. 
US Department of Health and Human Services (2012). Estimates of child care eligibility and receipt for fiscal year 2009. https://aspe.hhs.gov/system/files/pdf/76541/ib.pdf $(14 / 06 / 2017)$.

US Department of Health and Human Services (2016). Welfare indicators and risk factors. Fifteenth report to Congress. https://aspe.hhs.gov/pdf-report/ welfare-indicators-and-risk-factors-fifteenth-report-congress (06/11/2016).

Whelan, S. (2010). The take-up of means-tested income support. Empirical Economics, 39 (3), $847-875$. 


\section{A A theoretical framework of welfare take-up and social stigma}

In this section, we develop a framework for the individual decision to take up a welfare benefit under social image concerns that allows us to derive testable hypotheses. Our modeling of social stigma follows the same logic as models of social image concerns in the context of pro-social behavior: see, for instance, Bénabou and Tirole (2006).

Suppose an individual i's utility is given by

$$
u_{i}(c, t, s, d)=c+d t-d\left(s+\alpha_{i}\right)
$$

where $c$ is the level of consumption without a transfer, $t$ is the transfer, $d \in\{0,1\}$ denotes the decision whether or not to take up a transfer if eligible, and $s$ denotes the stigma costs associated with taking up the transfer. The parameter $\alpha_{i} \in[0, A]$ varies across individuals and specifies the moral disutility that an individual associates with receiving a transfer. This disutility may reflect attitudes with respect to earned entitlements and redistribution.

Assumption 1. Each individual's attitude $\alpha_{i}$ is independently drawn from a distribution that is characterized by a function $F$, which is continuous, differentiable, and strictly increasing over its support $[0, A]$. Denote the associated density by $f(\cdot)$.

Furthermore, individuals differ in their ability $\theta_{i}$. Both, the realized consumption level and the size of the transfer, which an individual is eligible to, may depend on ability, $c=c\left(\theta_{i}\right), t=$ $t\left(\theta_{i}\right)$. Staying close to our design and to the design of typical welfare programs, the size of the possible transfer is determined by an eligibility criterion that depends on ability. In particular, upon being eligible, an individual can only decide whether or not to take the transfer up but cannot influence the size of the transfer. For simplicity, and to fit our experimental design, we assume that only one transfer level is available and all individuals below a cutoff ability level are eligible.

Assumption 2. Each individual's ability $\theta_{i}$ is independently drawn from a distribution that is characterized by a function $H$, which is continuous, differentiable, and strictly increasing over its support $[0, \Theta]$. Denote the associated density by $h(\cdot)$.

Assumption 3. An individual is eligible to claim a transfer of a fixed size $\bar{t}$ if and only if here ability does not exceed a threshold level $\hat{\theta} \in(0, \Theta)$.

The stigma costs, $s=\rho_{A} R_{A}+\rho_{B} R_{F}$, are increasing to the extent that taking up the transfer is associated with ability stigma, $R_{A}$, or free-rider stigma, $R_{F}$, and the parameters $\rho_{A}>0$ and $\rho_{F}>0$ are the marginal disutilities associated with ability stigma and free-rider stigma, respectively.

The ability stigma term $R_{A}$ depends on the inferences made about an individual's ability $\theta_{i}$ upon observing the take-up of the transfer. It captures the idea that individuals may feel stigmatized because taking up a transfer reveals that they are less able; i.e., the decision to take the transfer may signal inferior ability because only less able individuals are eligible for the transfer. The free-rider stigma term $R_{F}$ depends on the inference about an individual's attitude 
$\alpha_{i}$ upon observing her to take up the transfer. It accounts for the fact that individuals may feel stigmatized because taking up the transfer reveals that they are willing to live off others; i.e., the take-up decision reveals something about an individual's attitude toward receiving money from others as measured by $\alpha$.

Our notion of ability signaling relates to statistical stigma in Besley and Coate (1992) and our notion of free-rider signaling bears similarity with their concept of taxpayer resentment. Relatedly, Stuber and Schlesinger (2006) discuss identity-related stigma as opposed to treatment stigma. See also Rainwater (1982). An extended model can include the role of laziness or effort signaling for the take-up decision in a similar way. But since effort is a choice variable itself, the model would then have to account for the trade-off between the disutilities of effort and laziness signaling. Therefore, the model would need to incorporate the effort choice explicitly. As the take-up decision in our experiment is only informative about ability, we abstract from effort in the model.

Stigma depends on the inferences that can be made about claimants and, therefore, stigma depends on the eligibility criterion. We specify each stigma term as a function of the expected deviation from the unconditional inference about an individual's ability $\theta$, and attitude $\alpha$, respectively. Both stigmata also depend on the degree of public exposure $\lambda$. We assume there are two functions $h_{1}(\cdot)$ and $h_{2}(\cdot)$, increasing in both arguments, such that

$$
\begin{gathered}
R_{A}(\hat{\theta}, \lambda)=\lambda h_{1}(E[\theta]-E[\theta \mid \theta \leq \hat{\theta} \wedge d=1]) \quad \text { and } \\
R_{F}(\hat{\theta}, \lambda)=\lambda h_{2}(E[\alpha]-E[\alpha \mid \theta \leq \hat{\theta} \wedge d=1])
\end{gathered}
$$

By definition, the stigma terms are always positive if some, but not all, individuals decide to take up the transfer. They are null if nobody or everyone takes the transfer.

We assume that an individual will not experience stigma if the take-up decision remains private $(\lambda=0)$. Note that her attitude $\alpha$ may still lead her to not take up a transfer of size $t$ in a private situation if $t<\alpha$. If the take-up decisions are public, take-up behavior is informative of an individual's ability $\theta$ and her attitude $\alpha$ such that stigma becomes decision-relevant. As $R_{A}$ and $R_{F}$ are increasing in $\lambda$, higher public scrutiny intensifies the feeling of being stigmatized. By specifying that stigma enters utility only if a transfer is taken up ( $d s$ in the utility in (4)), we have implicitly assumed that individuals do not worry about inferences about their type when they do not claim a transfer. We do this for simplification. ${ }^{19}$

The decision of an individual with attitude $\alpha$ with respect to taking up the transfer $(d=1)$ or not $(d=0)$ depends on the trade-off in utilities and the individual will take the transfer if

\footnotetext{
${ }^{19}$ We thank an anonymous referee for pointing out that image terms may also be associated with not taking up a transfer. These image terms may also enter the individual's decision problem. Generalizing our framework, these terms would take the form $R_{A}(d=0, \hat{\theta}, \lambda)=h_{1}(E[\theta]-E[\theta \mid$ not eligible or (eligible and $\left.d=0)]\right)$ and $R_{F}(d=$ $0, \hat{\theta}, \lambda)=h_{1}(E[\alpha]-E[\alpha \mid$ not eligible or (eligible and $d=0)]$ ), for ability and free-rider stigma, respectively. These two image terms will always be negative whereas those associated with take-up are positive, thus making nontake-up even more attractive as compared to claiming the transfer. While the specific equilibrium threshold will change, the results will remain qualitatively unchanged. Such a generalization will introduce an additional effect into the ability stigma, which was previously present only for free-rider stigma: The more individuals that do not claim, even though they are eligible, the lower is the ability inference associated with non claiming the transfer so that the relative stigma from take-up decreases until an equilibrium is reached. As $\theta$ and $\alpha$ are unrelated to each other, the equilibrium threshold is again determined solely through the attitude toward living off others, $\tilde{\alpha}$.
} 
doing so yields at least the same utility as not taking it. Then, for every individual i, who is eligible to the transfer and is claiming the transfer, it must be true that $u_{i}\left(c\left(\theta_{i}\right)+\bar{t}, s, d=1\right) \geq$ $u\left(c\left(\theta_{i}\right), s, d=0\right)$. This expression is equivalent to

$$
\alpha_{i} \leq \bar{t}-\rho_{A} R_{A}(\hat{\theta}, \lambda)-\rho_{F} R_{F}(\hat{\theta}, \lambda)
$$

If equation 5 is fulfilled for all $\alpha \in[0, A]$, all individuals claim the transfer independent of their inclination to take money from others. Similarly, if there is no $\alpha \in(0, A)$ for which 5 holds, no individual will claim the transfer even if she is the one most willing to live off others. To focus on the interesting cases, we assume that the tradeoff is negative for some $\alpha$ and positive for others. This assumption is also consistent with our experimental results showing that take-up is neither zero nor complete. See section 3 .

Define $G(\alpha)=\bar{t}-\rho_{A} R_{A}(\hat{\theta}, \lambda)-\rho_{F} R_{F}(\hat{\theta}, \lambda)-\alpha$. We make two technical assumptions.

Assumption 4. Assume that there exist $\alpha, \alpha^{\prime} \in[0, A]$ such that $G(\alpha)<0<G\left(\alpha^{\prime}\right)$.

Assumption 5. Assume that the distribution of attitudes fulfills $f(\alpha)<\left(\rho_{F} \alpha\right)^{-1}$ for all $\alpha \in$ $[0, A]$.

Assumption 4 implies that an individual with attitude $\tilde{\alpha}$ exists who is just indifferent between taking up the transfer and not taking it. Assumption 5, ensures that the threshold value determined by equation 5 is unique. It is, for instance, fulfilled if attitudes are uniformly distributed on $[0,1]$ and the marginal utility from free-rider stigma is less than one, $\rho_{F}<1$.

Then, the trade-off in equation 5 defines a unique cutoff value $\tilde{\alpha}$ such that all individuals with $\alpha_{i} \leq \tilde{\alpha}$ claim the transfer and those with $\alpha_{i}>\tilde{\alpha}$ do not claim the transfer. We assume that the transfer is taken up in case of indifference, but, as we assume a continuous distribution of types, this assumption is immaterial to our results. The implied take-up rate is given by the fraction of individuals with an attitude below the threshold, i.e., $F(\tilde{\alpha})$.

Proposition 1. Behavior is characterized by a cutoff strategy. For a cutoff value $\tilde{\alpha}$ implicitly defined by $G(\tilde{\alpha})=0$, individuals with $\alpha<\tilde{\alpha}$ take the transfer, and individuals with $\alpha>\tilde{\alpha} d o$ not take the transfer. The take-up rate is given by $F(\tilde{\alpha})$.

Proof. Suppose assumptions 4 and 5 hold. As we have also assumed that the distribution of $\alpha$ is continuous, we know that the free-rider stigma expression is continuous and, therefore, $G(\alpha)$ is continuous. By Assumption 4, we find $\alpha, \alpha^{\prime} \in[0, A]$ such that $G(\alpha)<0<G\left(\alpha^{\prime}\right)$. As $G(\alpha)$ is defined on the closed interval $[0, A]$, the intermediate value theorem tells us that a value $\tilde{\alpha}$ exists for which $G(\tilde{\alpha})=0$. By Assumption 5, we have $\frac{d}{d \alpha}\left(t-\rho_{A} R_{A}(\hat{\theta}, \lambda)-\rho_{F} R_{F}(\hat{\theta}, \lambda)-\alpha\right)=$ $-\rho_{F} \partial R_{F}(\hat{\theta}, \lambda) / \partial \alpha-1=\rho_{F} \alpha f(\alpha)-1<0$. Thus, the trade-off defined in equation 5 only holds for equality at most once and $\tilde{\alpha}$ with $G(\tilde{\alpha})=0$ is unique.

Using implicit differentiation, we analyze how the threshold value and, thus, the take-up rate changes in response to changes in the economic trade-off. These comparative statics are the basis for our design and the following two corollaries are the foundation for the predictions of section 2 . 
Corollary 1. Take-up of the transfer is lower if the decision to take up the transfer is more visible, $F\left(\tilde{\alpha}\left(\lambda^{\prime}\right)\right)<F\left(\tilde{\alpha}(\lambda)\right.$ for $\lambda^{\prime}>\lambda$.

Proof. The threshold from equation 5 decreases if the take-up decision is more publicly exposed. The denominator is positive by Assumption 5 .

$$
\frac{d \tilde{\alpha}}{d \lambda}=-\frac{\rho_{A} \partial R_{A}(\hat{\theta}, \lambda) / \partial \lambda+\rho_{F} \partial R_{F}(\hat{\theta}, \lambda) / \partial \lambda}{\rho_{F} \partial R_{F}(\hat{\theta}, \lambda) / \partial \tilde{\alpha}+1}<0
$$

Intuitively, if claiming the transfer is more exposed, the disutility from the associated stigma weighs more heavily such that only individuals with little concern about others' money, i.e. small $\alpha$, claim the transfer. This threshold translates directly into the rate of take-up so that we obtain the above result with respect to the effect of making the take-up decision public.

Denote the difference in take-up due to increased visibility by $\Delta=F\left(\tilde{\alpha}\left(R_{A}(\hat{\theta}, \lambda), R_{F}(\hat{\theta}, \lambda)\right)-F\left(\tilde{\alpha}\left(R_{A}\left(\hat{\theta}, \lambda^{\prime}\right), R_{F}\left(\hat{\theta}, \lambda^{\prime}\right)\right)\right)\right.$. This is the "stigma effect", and it depends on the size of both ability and free-rider stigma which in turn depend on the visibility and the eligibility criterion because only those who are eligible can decide to claim a transfer.

Corollary 2. The stigma effect is larger if take-up is more informative about ability, i.e., if the eligibility criterion is stricter, $\hat{\theta}^{\prime}<\hat{\theta} \Rightarrow \Delta\left(R_{A}^{\prime}, R_{F}\right)>\Delta\left(R_{A}, R_{F}\right)$.

Proof. Conditional on the take-up decision being public, the threshold from equation 5 decreases if the decision to take-up the transfer leads to a more negative signal about the individual's ability due to the lower ability threshold for eligibility. Formally, $R_{A}(\hat{\theta}, \lambda)$ (which is weakly positive) increases to $R_{A}\left(\hat{\theta}^{\prime}, \lambda\right)$ because $R_{A}=R_{A}(\hat{\theta}, \lambda)=h_{1}((E[\theta]-E[\theta \mid \theta \leq \hat{\theta}]), \lambda)<R_{A}^{\prime}=$ $R_{A}\left(\hat{\theta}^{\prime}, \lambda\right)=h_{1}\left(\left(E[\theta]-E\left[\theta \mid \theta \leq \hat{\theta}^{\prime}\right]\right), \lambda\right)$. Intuitively, with a higher ability stigma, only individuals with small $\alpha$, i.e. little concern about others' money, take the transfer, meaning that the freerider stigma associated with take-up also increases.

$$
\frac{d \tilde{\alpha}}{d R_{A}(\hat{\theta}, \lambda)}=-\frac{\rho_{A}}{\rho_{F} \partial R_{F}(\hat{\theta}, \lambda) / \partial \tilde{\alpha}+1}<0
$$

This derivative is unambiguously negative because the free-rider stigma associated with taking up the transfer is decreasing with $\tilde{\alpha}$. The more individuals take the transfer, the higher is the conditional expectation of their attitude, thus, on average, the welfare claimant is less willing to take money from others and less stigmatized. If all take the transfer, the claimant does not differ in his or her attitude from the average population and the free-rider stigma is zero. Thus, we find that the stigma effect of publicity is larger if eligibility to the transfer sends a more negative signal about ability (lower $\hat{\theta}$ ) than a more positive one (higher $\hat{\theta}$ ) or is unrelated to ability $(\hat{\theta}=\Theta)$. 


\section{B Additional tables}

Table 6: Descriptive statistics

\begin{tabular}{lrrrrr}
\hline & $\mathrm{n}$ & Mean & Std. Dev. & Minimum & Maximum \\
\hline Male & 441 & 0.592 & 0.492 & 0 & 1 \\
Age & 441 & 23.900 & 4.234 & 16 & 48 \\
Studying & 441 & 0.952 & 0.213 & 0 & 1 \\
Working & 441 & 0.297 & 0.457 & 0 & 1 \\
Subject related to Econ & 441 & 0.243 & 0.429 & 0 & 1 \\
Experimental Experience & 441 & 1.889 & 0.995 & 0 & 3 \\
Correct answers in quiz & 441 & 9.574 & 2.591 & 3 & 17 \\
\hline
\end{tabular}


Table 7: Regression of individual take-up on treatment dummies and controls

\begin{tabular}{lcccc}
\hline & Redistribution & Redistribution & Subsidized & Subsidized \\
\hline Public & $-0.189^{* * *}$ & $-0.189^{* * *}$ & -0.021 & -0.021 \\
& $(0.032)$ & $(0.033)$ & $(0.047)$ & $(0.047)$ \\
Quiz & 0.017 & 0.017 & 0.025 & 0.057 \\
& $(0.037)$ & $(0.038)$ & $(0.049)$ & $(0.051)$ \\
Public x Quiz & $-0.114^{* *}$ & $-0.114^{* *}$ & $-0.153^{* *}$ & $-0.153^{* *}$ \\
& $(0.050)$ & $(0.050)$ & $(0.072)$ & $(0.073)$ \\
Age (from 20) & & $0.009^{* *}$ & & -0.007 \\
& & $(0.004)$ & & $(0.005)$ \\
Male & & $-0.074^{*}$ & & $-0.086^{*}$ \\
& & $(0.040)$ & & $0.050)$ \\
Share male subjects & & 0.027 & & 0.076 \\
& & $(0.023)$ & & $(0.059)$ \\
Male x Share male subjects & & 0.012 & & -0.038 \\
Constant & $0.862^{* * *}$ & $0.037)$ & & $(0.079)$ \\
& $(0.027)$ & $(0.036)$ & $0.917^{* * *}$ & $0.968^{* * *}$ \\
Adj. R2 & 0.083 & 0.096 & $0.040)$ & $(0.043)$ \\
N & 324 & 324 & 117 & 0.048 \\
\hline
\end{tabular}

Notes: Table shows OLS regression results of equation (2) with standard errors clustered on the subject level. We regress individual take-up on treatment dummies for public transfer, quiz and their interaction. In columns 2 and 4, we add demographic controls. The coefficient of "Public" is the within-subject treatment difference between public and private transfer in the random treatment. The coefficient of "Quiz" is the between-subject treatment difference between quiz and random in the private transfer treatment. The coefficient of the interaction term corresponds to the diff-in-diff estimator. The constant is the average take-up rate of a private transfer in the random treatment. "Share male subject" is z-standardized and to be interpreted as deviations from the mean. ${ }^{*} p<0.10,{ }^{* *} p<0.05,{ }^{* * *} p<0.01$ 
Table 8: Post-experimental questionnaire responses regarding signaling

\begin{tabular}{lccr}
\hline Statement & \multicolumn{2}{c}{$\begin{array}{c}\text { Rel. Frequency } \\
\text { Quiz }\end{array}$} & Random \\
\hline "The participant in rank 3 has poor knowledge" & \\
Strongly Disagree & 0 & 28.17 & 75.47 \\
& 1 & 29.58 & 10.69 \\
& 2 & 19.72 & 10.06 \\
& 3 & 19.25 & 3.14 \\
Strongly Agree & 4 & 3.29 & 0.63 \\
\hline N & & 213 & 159 \\
\hline \multirow{4}{*}{ "The participant in rank 3 had bad luck" } & \\
Strongly Disagree & 0 & 7.69 & 14.49 \\
& 1 & 14.96 & 5.80 \\
& 2 & 26.50 & 13.53 \\
Strongly Agree & 4 & 37.18 & 14.98 \\
\hline N & 4 & 13.68 & 51.21 \\
\hline
\end{tabular}

Notes: Table shows to what extent subjects agree to the respective statements from 0 (strongly disagree) to 4 (strongly agree). The number of observation differs since the first question was not included in the first three sessions.

Table 9: Post-experimental questionnaire responses regarding voting

\begin{tabular}{|c|c|c|c|}
\hline \multirow[t]{2}{*}{ Statement } & \multicolumn{3}{|c|}{ Rel. Frequency } \\
\hline & & Pro Public & Contra Public \\
\hline \multicolumn{4}{|c|}{ "Free-riders should be identified as such" } \\
\hline \multirow[t]{4}{*}{ Strongly Disagree } & 0 & 10.64 & 34.43 \\
\hline & 1 & 23.40 & 27.87 \\
\hline & 2 & 29.79 & 24.59 \\
\hline & 3 & 21.28 & 8.20 \\
\hline Strongly Agree & 4 & 14.89 & 4.92 \\
\hline $\mathrm{N}$ & & 94 & 122 \\
\hline
\end{tabular}

\begin{tabular}{lrrr} 
"I want to reduce the take-up probability to raise my payout" \\
Strongly Disagree & 0 & 9.57 & 27.87 \\
& 1 & 11.70 & 20.49 \\
& 2 & 23.40 & 31.15 \\
& 3 & 28.72 & 13.11 \\
Strongly Agree & 4 & 26.60 & 7.38 \\
\hline N & & 94 & 122 \\
\hline \multicolumn{4}{l}{ "I don't want the claimant to be ashamed" } \\
Strongly Disagree & 0 & 18.09 & \\
& 1 & 24.47 & 2.46 \\
& 2 & 39.36 & 4.92 \\
& 3 & 8.51 & 10.66 \\
Strongly Agree & 4 & 9.57 & 22.13 \\
\hline N & & 94 & 59.84 \\
\hline
\end{tabular}

Notes: Table shows to what extent subjects agree to the respective statements from 0 (strongly disagree) to 4 (strongly agree). Only subjects in ranks 1 and 2 are considered. 


\section{Additional figures}

Figure 5: Take-up rate by correct quiz answers $(\mathrm{n}=165)$

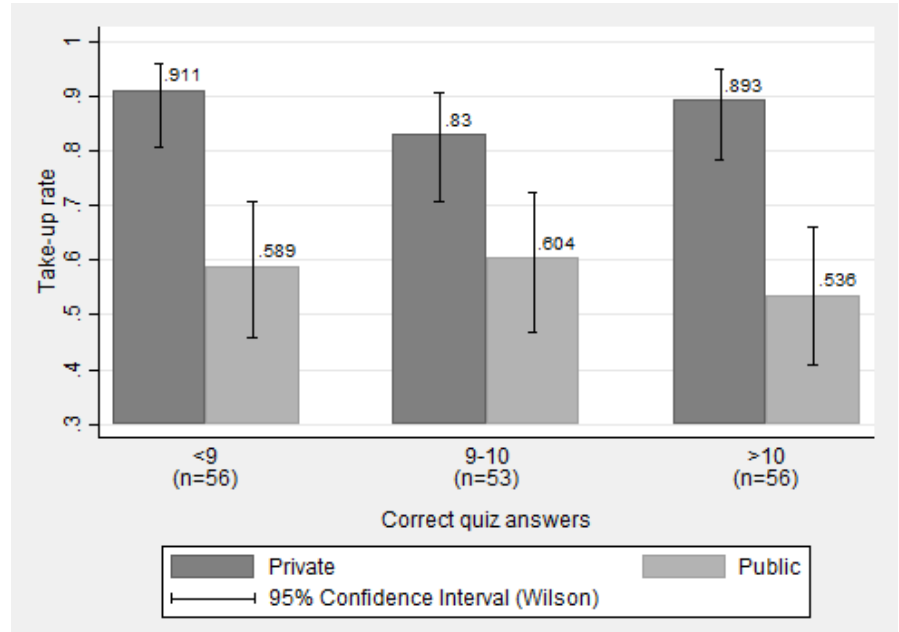

Notes: Plot shows the take-up rate in the public and private treatment conditional on the number of correctly answered quiz questions, which we consider a proxy for ability. We include only subjects in the redistributive quiz treatment. There are no significant differences in take-up between ability groups in either the public or private treatments. 
Figure 6: Take-up rate by working status $(n=165)$

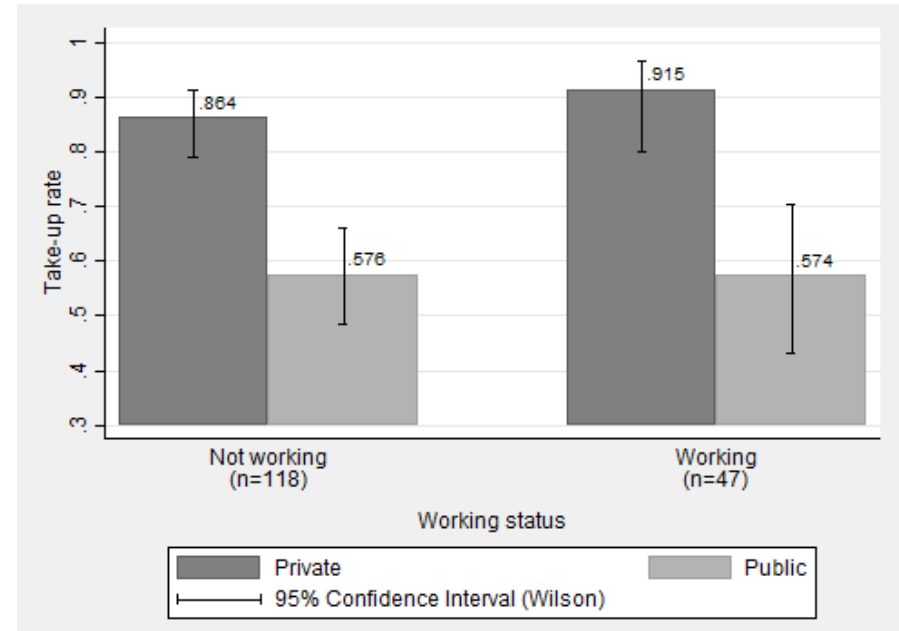

Notes: Plot shows the take-up rate in the public and private treatment conditional on working status. We include only subjects in the redistributive quiz treatment. There are no significant differences in take-up between working and not working in either the public or private treatments.

Figure 7: Take-up rate by gender $(\mathrm{n}=165)$

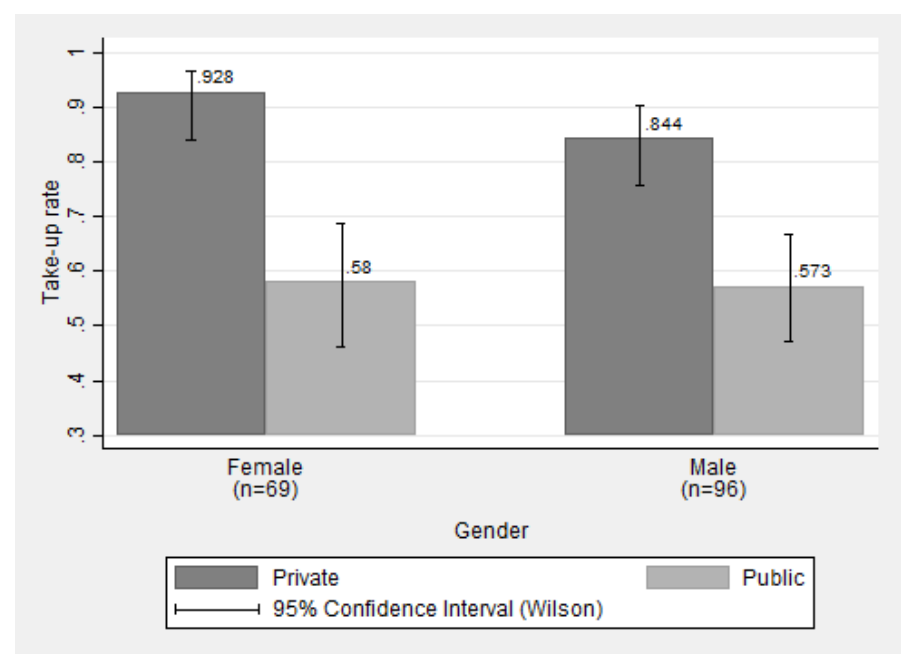

Notes: Plot shows the take-up rate in the public and private treatment conditional on gender. We include only subjects in the redistributive quiz treatment. There are no significant differences in take-up between male and female in either the public or private treatments. 


\section{Instructions (translated from German)}

\section{Welcome to our experiment!}

During the experiment you are not allowed to use electronic devices or communicate with other participants. Please only use the programs and functions provided for the experiment. Please do not talk to other participants. If you have a question, please raise your hand. We will come to you and will quietly answer your question. Please never ask your questions aloud. If the question is relevant for all participants, we will repeat it and answer it loudly. If you do violate these rules, we must exclude you from the experiment and the payoff.

The following instructions describe the process of the experiment and are the same for all participants. You can earn money in this experiment. The level of your payout depends on your decisions, on the decisions of other participants, and on chance. Please carefully read the instructions. You can leave the experiment at any time. If you want to do so, please raise your hand. You will only receive payment if you stay until the end of the experiment.

\section{Quiz}

In this experiment, you and two other participants will form a group. The group will remain the same for the entire experiment. All participants will first answer a quiz. You receive 18 questions on different domains of general knowledge. There are four possible answers to each question, of which exactly one is correct. You will obtain one point for each question answered correctly. You do not receive any point for questions that were not answered or incorrectly answered. You have six minutes to work on the quiz. After that, all given responses will be submitted.

[Quiz: Your pay-off depends on how well you solve your tasks in comparison to the other two group members. The member of the group who has collected the biggest amount of points after six minutes receives the first rank, the member of the group with the second biggest amount of points receives the second rank and the member of the group with the third biggest amount of points receives the third rank. If two or three members of the group have the same amount of points, it will be determined randomly who gets the higher rank.]

[Random: Independently of the amount of collected points, each group member will be randomly assigned to a rank that is relevant for the rest of the experiment. Your rank does in no way depend on your performance in the quiz.]

\section{Pay-Off}

The payoff to one participant depends on her rank. There are two possible modes of payoff: payoff mode $\mathrm{A}$ and payoff mode $\mathrm{B}$.

\section{[Redistribution:]}

[Subsidized:]

[Redistribution: Mode A differs from mode $\mathrm{B}$ in that the participant in the third rank receives a transfer from the participants in the first and second ranks.] 


\begin{tabular}{cll}
\hline Rank & Mode A & Mode B \\
\hline 1 & 16 Euro & 14 Euro \\
2 & 11 Euro & 10 Euro \\
3 & 6 Euro & 9 Euro \\
\hline & & \\
\hline Rank & Mode A & Mode B \\
\hline 1 & 16 Euro & 16 Euro \\
2 & 11 Euro & 11 Euro \\
3 & 6 Euro & 9 Euro \\
\hline
\end{tabular}

[Subsidized: Mode A differs from mode B in that the participant in the third rank receives a transfer.]

Which of these payoff modes will be applied depends on your decisions and the decisions of the other participants in the second part of the experiment. You will receive the instructions for the second part upon completing the first part.

\section{Second part of the experiment}

[to be handed out after the first part has ended]

The second part of the experiment will decide which of the two payoff modes will be applied. In each group, this depends on the decisions of the group member in the third rank. If the group member in the third rank decides to take the transfer, payoff mode $\mathrm{B}$ will be applied. If the group member in the third rank decides not to take the transfer, payoff mode A will be applied.

\section{Stage 1}

You now must make a binding decision on whether you would like to take the transfer in the case you are placed in the third rank. You will only find out about your rank in stage 2. If you end up in the third rank, the decision that you now make will be applied. On two consecutive screens, you will now receive information on the conditions under which you can receive the transfer. On each of these screens, you have to decide on whether you would take the transfer under the given conditions and in case you end up in the third rank. Which of these conditions will be applied is determined in stage 2. Please consider that your decision is binding and irreversible for the rest of the experiment.

\section{Stage 2}

[Quiz: After making your decision in stage 1, you will find out about the rank you achieved in your group.] [Random: After taking your decision in stage 1, you will find out about the rank you were randomly assigned to.] For each group it will now be decided which of the conditions shown in stage 1 will be applied. Out of the two possible conditions, each member of the group will now pick the one that should be applied according to his/her opinion. In each group, one participant will be randomly picked and her decision will be applied in her group. 


\section{Payoff}

Remember: the pay-off depends on the rank. Whether payoff mode A or B will be applied depends on the group member in the third rank. If that member decided to take the transfer, mode $\mathrm{B}$ will be applied. If that member decided against the transfer, mode A will be applied to the pay-off. It is now relevant how the group member on the third rank decided under the conditions picked by the group.

[Redistribution:]

\begin{tabular}{cll}
\hline Rank & Mode A & Mode B \\
\hline 1 & 16 Euro & 14 Euro \\
2 & 11 Euro & 10 Euro \\
3 & 6 Euro & 9 Euro \\
\hline
\end{tabular}

[Subsidized:]

\begin{tabular}{cll}
\hline Rank & Mode A & Mode B \\
\hline 1 & 16 Euro & 16 Euro \\
2 & 11 Euro & 11 Euro \\
3 & 6 Euro & 9 Euro \\
\hline
\end{tabular}

Please answer the attached control questions and raise your hand when you are done. An experimenter will then come to you to check your answers. If you have any questions, please raise your hand.

\section{Questionnaire}

1. Does your rank depend on your performance in the quiz? Yes/No

2. [Quiz: Assume you scored the second highest number of points in your group.] [Random: You were randomly assigned to the second rank.] In the first stage, the two other group members decided to take the transfer under both conditions.

(a) What is your payoff?

(b) What is the payoff of the group member on rank 1 ?

3. Assume that you decided for a certain condition in stage 2. The two other group members decided for the other condition. Which condition is relevant for payoff?

- The condition that I chose.

- The condition that the other two group members chose.

- Both conditions are possible. 


\section{E Screenshots}
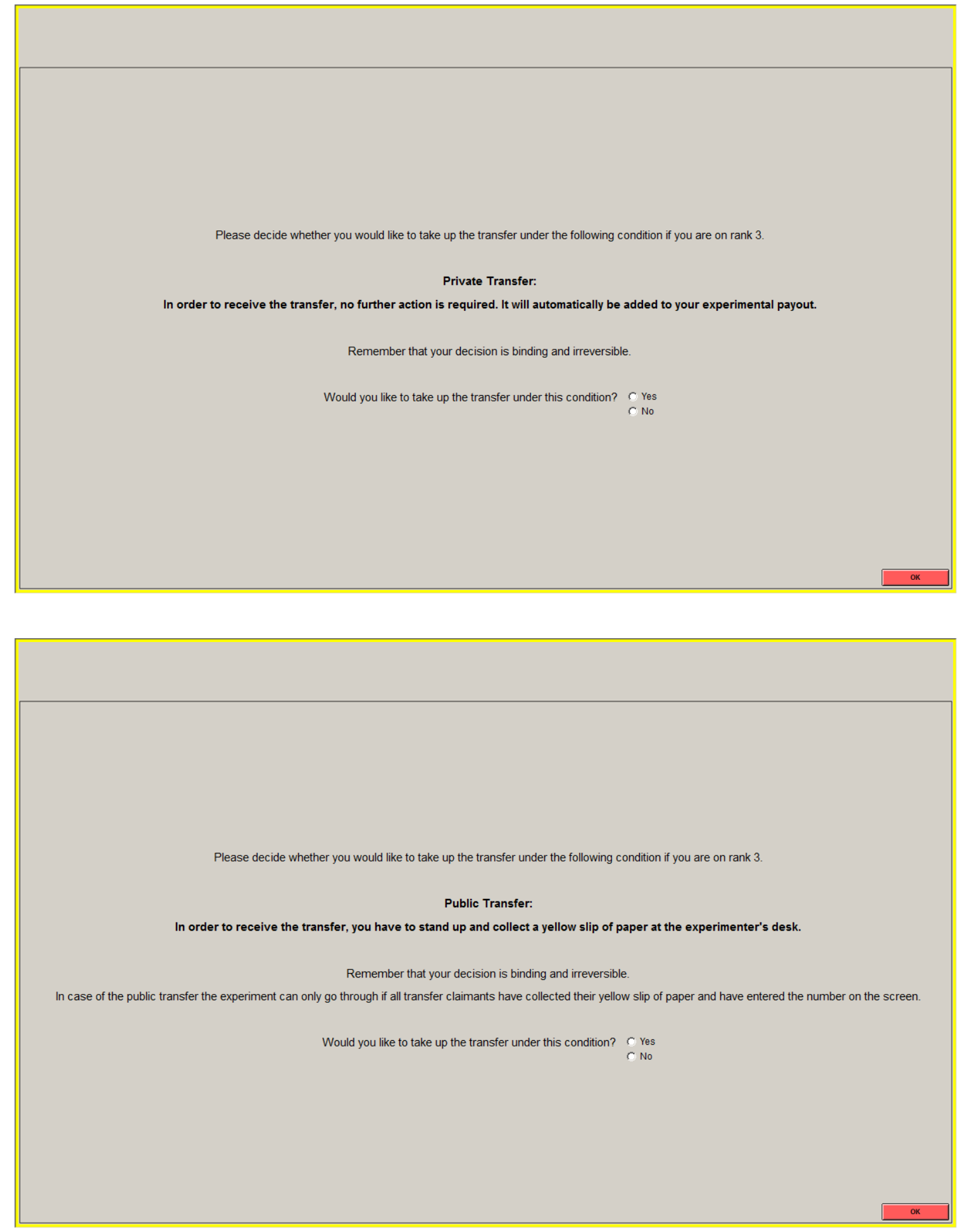

Figure 8: Take-up conditions presented on-screen in randomized order (translated from German) 


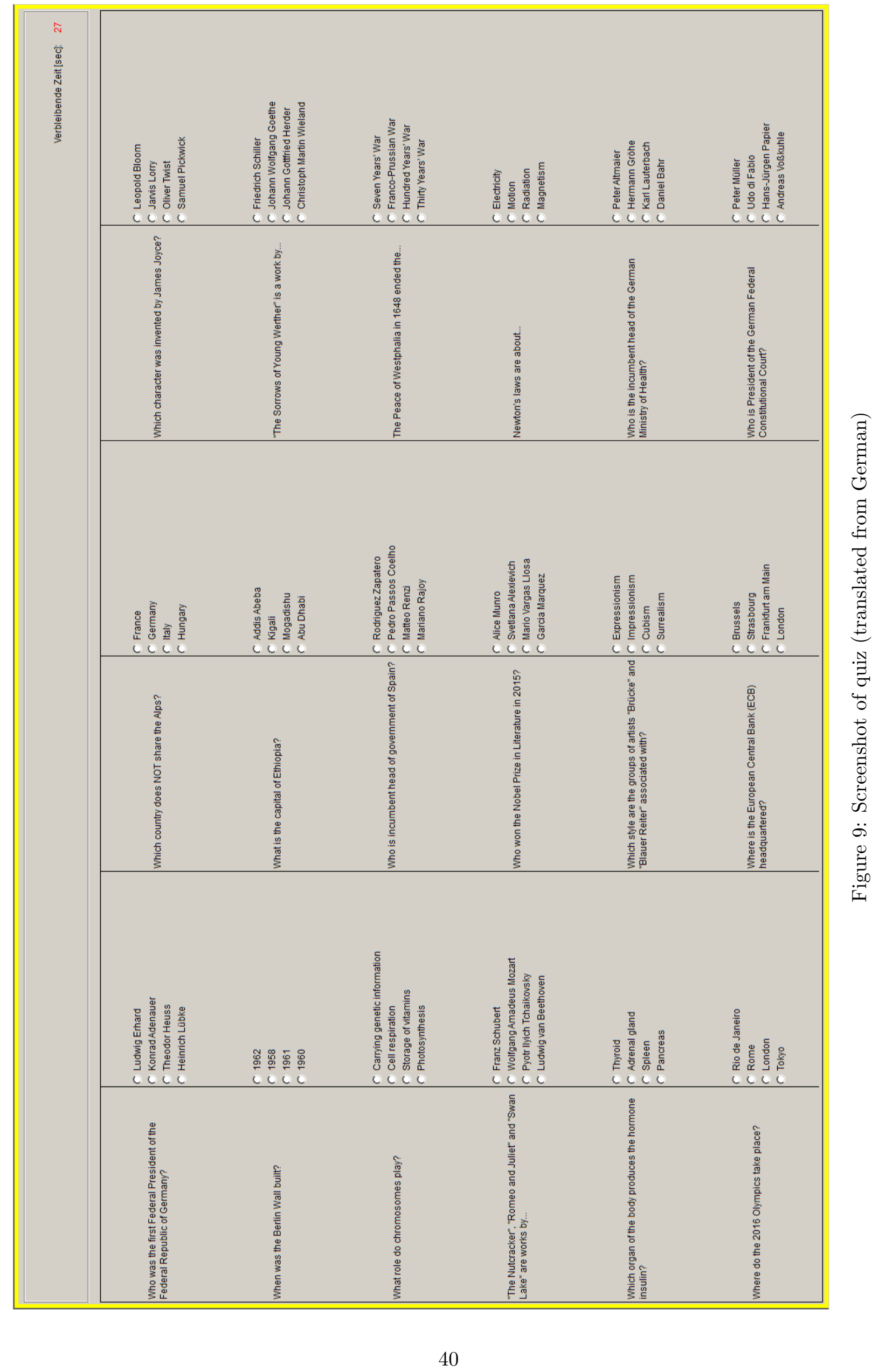

